\title{
A importância do tamanho das firmas para o crescimento econômico das microrregiões brasileiras
}

\author{
Douglas Mesquita Carneiro \\ Universidade Luterana do Brasil/ Campus Torres \\ Carlos Eduardo Lobo e Silva \\ Pontifícia Universidade Católica do Rio Grande do sul
}

\section{Resumo}

O objetivo deste trabalho é analisar a importância do tamanho das firmas industriais para o crescimento econômico das 558 microrregiões do Brasil no período de 1999 a 2009. Para tanto, fez-se uso de estimações de dados em painel via system GMM e uma análise de econometria espacial. As estimativas para o Brasil como um todo mostram que a presença de grandes empresas do setor industrial contribuiu positivamente para o crescimento econômico das microrregiões, enquanto que as pequenas empresas apresentaram uma relação negativa com o crescimento. A presença de heterogeneidade espacial na amostra é caracterizada por dois regimes espaciais diferentes no que tange à renda per capita. A análise de cada regime espacial separadamente aponta que a relação entre tamanho de empresa e crescimento econômico nas regiões mais ricas permanece a mesma, enquanto que, nas regiões de Produto Interno Bruto - PIB per capita menor, o tamanho da empresa não influencia no crescimento econômico.

Palavras-chave: Tamanho das firmas. Crescimento econômico. Spillovers espaciais.

\section{The importance of firm size for the economic growth of brazilian micro-regions}

\begin{abstract}
The objective of this work is to analyze the role of firm size for the economic growth of the 558 Brazilian micro-regions from 1999 to 2009. It was used a panel data estimations with GMM system and a spatial econometric analysis. Estimates for Brazil as a whole show that the presence of large companies in the industrial sector has contributed positively to the economic growth of regions, whereas small businesses and economic growth presented a negative relationship. The presence of spatial heterogeneity in the sample is characterized by two different spatial clusters with respect to per capita income. The analysis of each spatial clusters separately points out that the relationship between firm size and economic growth in the richest regions remains the same, while in the regions of lower GDP per capita, the size of the firms does not influence the economic growth.
\end{abstract}

Keywords: Firms size. Economic growth. Spatial spillovers. 


\section{La importancia del tamaño de las firmas para el crecimiento económico de las microrregiones brasileñas}

\section{Resumen}

El objetivo de este trabajo es analizar la importancia del tamaño de las firmas industriales para el crecimiento económico de las 558 microrregiones de Brasil en el período de 1999 a 2009. Se utilizó estimaciones de datos en panel a través del sistema GMM y un análisis de econometría espacial, considerando heterogeneidad y dependencia espacial. Las estimaciones para Brasil como un todo muestran que la presencia de grandes empresas del sector industrial contribuyó positivamente al crecimiento económico de las microrregiones, mientras que las pequeñas empresas presentaron una relación negativa con el crecimiento. La presencia de heterogeneidad espacial en la muestra se caracteriza por dos regímenes espaciales diferentes en lo que se refiere al ingreso per cápita. El análisis de cada régimen espacial por separado apunta que la relación entre tamaño de empresa y crecimiento económico en las regiones más ricas sigue siendo la misma, mientras que en las regiones de PIB per cápita menor, el tamaño de la empresa no influye en el crecimiento económico.

Palavras clave: Tamaño de las firmas. Crecimiento económico. Spillovers espaciales.

\section{Introdução}

O reconhecimento da importância econômica das micro e pequenas empresas, especialmente na geração de empregos, faz com que instituições brasileiras e internacionais - como Serviço Brasileiro de Apoio às Micro e Pequenas Empresas - SEBRAE e o Banco Mundial ${ }^{1}$ - apoiem as atividades das empresas locais de menor porte. No extremo oposto, o Brasil tem assistido, nas últimas décadas, a uma guerra fiscal entre estados e municípios, cujo objetivo de todos os envolvidos é atrair grandes empresas para a região, por meio de subsídios e concessões².

Portanto, há esforços e recursos públicos direcionados tanto à atração de grandes empresas quanto à criação e fortalecimento das micro e pequenas empresas. Entretanto, pouco se discute no Brasil a respeito da conexão entre tamanho de empresa e crescimento econômico regional. Nesse caso, a ausência de uma discussão embasada em dados obtidos com rigor metodológico não parece ser falha dos políticos e gestores públicos, mas consequência da carência de trabalhos acadêmicos sobre o tema, como será visto em seguida.

$\mathrm{Na}$ literatura acadêmica internacional, a discussão, apesar de nada consensual, traz resultados e conclusões que podem orientar até certa medida - formuladores de políticas públicas que buscam dinamizar a economia local, através do apoio às atividades produtivas da região (Loveridge e Nizalov, 2007).

Em favor das grandes empresas, alguns fatores são ressaltados pela literatura. A maior capacidade de inovar e de explorar
${ }^{1}$ Sobre projetos de apoio às micro e pequenas empresas do Banco Mundial, ver Beck et. al.(2005).

2 Iniciada na década de 1990, a guerra fiscal ainda é tema de acalorados debates no Congresso Nacional. Veja, por exemplo, http://www1.folha.uol.co $\mathrm{m} . \mathrm{br} / \mathrm{mercado} / 2015 / 04 / 1$ 613568-senado-aprovavalidacao-de-incentivosfiscais-de-estados.shtml 
completamente os avanços inovadores são apontados como características marcantes das grandes empresas (Lee et. al., 2012; Pagano e Schivardi, 2003).

Associado à inovação está uma maior produtividade por parte dessas empresas. De acordo com o Idson e Oi (1999), a forma de organização das grandes empresas permite a alocação de indivíduos mais produtivos, dado que estas empresas possuem tecnologias, equipamentos e organização do trabalho mais avançadas.

Outra característica associada às grandes empresas é o potencial exportador. Análises empíricas indicam que o potencial de exportação 3 é positivamente relacionado com o tamanho da empresa (Esteve-Perez et. al., 2005; Araujo e Hiratuka, 2006).

De Negri (2006) mostra também que a probabilidade da firma

3 Para uma revisão sobre a relação entre tamanho da firma e potencial exportador, veja também Silva (2012). se tornar exportadora aumenta na medida em que há ampliação na sua escala de produção. Finalmente, segundo Gomes e Ellery (2007), as exportadoras brasileiras são cerca de 6 vezes maiores que as firmas que não exportam, resultado semelhante ao dos Estados Unidos, cujas exportadoras são, em média, 5,6 vezes maior que firmas não exportadoras.

Tal relação pode ser proveniente tanto das economias de escala presentes nas grandes empresas (Liu e Shu, 2003), como maior acesso ao crédito por parte dessas empresas (Ling-Yee e Ogunmokum, 2001). Para Biesebroeck (2005), a maior disponibilidade de crédito para as grandes empresas também é fortemente correlacionada com a produtividade, gerando, assim, mais crescimento econômico.,

Por outro lado, as micro e pequenas empresas também possuem características próprias e que são importantes para uma maior eficiência econômica. As menores empresas estão geralmente associadas a taxas de crescimento do emprego maiores (Neumark et. al., 2001; Shaffer, 2006). Além do mais, as pequenas empresas são, na maioria das vezes, intensivas em trabalho, podendo, assim, ser um importante meio de geração de novos empregos e, consequentemente, redução do desemprego (Komarek e Loveridge, 2015; Perius e Wittmann, 2003). 
Alguns autores ressaltam que capacidade de inovação e ganhos de produtividade também podem ser características das pequenas empresas. Uma maior concorrência e o incentivo ao empreendedorismo, típicos de mercados fragmentados em pequenas empresas, podem introduzir novos produtos e/ou novos processos de produção, o que contribui para acelerar o ritmo do crescimento econômico (Acs e Audretsch, 2003; Beck et. al., 2005; Perius e Wittmann, 2003; Wong et. al. 2006).

Outra característica associada à importância das pequenas empresas está na capacidade de geração de clusters. Para La Rovere e Shehata (2006), as formações de arranjos empresariais de pequenas empresas podem ser vistas como estratégia de crescimento econômico local, dado o potencial de spillovers positivos gerados por esta associação.

Mesmo com as pequenas empresas apresentando características que podem elevar a eficiência econômica, os resultados empíricos da relação entre crescimento econômico e presença de pequenas empresas se mostram ambíguos, dependendo, na maioria das vezes, do nível de desenvolvimento do país ou região.

Em um contexto de regiões desenvolvidas, a literatura mostra que o impacto do empreendorismo, advindo da exploração de oportunidades empresariais, tem um impacto positivo no crescimento econômico (Mueller, 2007; Van Stel et. al., 2005). No entanto, o empreendedorismo tende a desempenhar um papel diferente de acordo com estágio de desenvolvimento econômico do país. Assim, a relação entre nível de empreendedorismo e crescimento econômico seria negativa para os países em desenvolvimento e positiva para os países desenvolvidos (Acs et. al., 2008; Van Stel et. al., 2005).

Considerando os estudos sobe o tema para a economia brasileira, Cravo (2010) e Cravo et. al. (2012) investigam exclusivamente a relação entre pequenas e médias empresas e o crescimento econômico. Os autores encontram evidências que sugerem uma relação negativa entre pequenas e médias empresas e crescimento econômico nas regiões brasileiras. Entretanto, ao se incorporar a variável capital humano na variável pequena e média empresa, a relação passa a ser positiva. Esse resultado sugere que as empresas com elevado nível de capital humano são capazes de gerar crescimento econômico.

A análise empírica presente neste artigo pretende contribuir para um debate não apenas pouco explorado na literatura acadêmica no Brasil, mas também essencial para orientar políticas públicas de desenvolvimento regional. Certamente, resultados empíricos sobre a relação entre tamanho das firmas e crescimento econômico podem trazer luz às decisões de estimular micro e pequenas empresas e/ou despender esforços para atrair e manter grandes empresas na economia local.

Dessa forma, este trabalho propõe diferentes modelos que, em seu conjunto, buscam robustez e consistências em seus resultados. Os modelos propostos permitem - em contraste com os demais artigos sobe o tema para a economia brasileira - estimar e comparar impactos advindos tanto da concentração de micro e pequenas empresas como da participação de grandes empesas na economia local. 
Para tanto, faz-se uso, inicialmente, de estimações por meio de system GMM. Essas estimações foram elaboradas utilizando variáveis normalmente utilizadas para modelar crescimento ${ }^{4}$, tais como: a população, a educação, a renda e mais a variável que indica tamanho das empresas. Posteriormente, analisa-se a relação entre tamanhos das firmas e crescimento econômico, levando em consideração a presença de spillovers geográficos, pois a desconsideração de aspectos como dependência espacial e heterogeneidade pode levar a problemas econométricos como viés de variável omitida e endogeneidade (Badinger et. al., 2004; Ertur e Koch, 2007; Mohl e Hagen, 2010).

Além desta introdução, o artigo será dividido em mais três seções. Na seção 2, são descritas as metodologias e o os dados utilizados neste estudo. A seção 3 traz uma análise exploratória dos dados e apresenta os principais resultados do trabalho. Em seguida, as considerações finais fecham o artigo.

\section{Aspectos metodológicos}

\subsection{Especificação dos modelos}

A estratégia empírica de analisar a importância do tamanho das empresas para o crescimento econômico das microrregiões é elaborada utilizam-se equações que relacionam crescimento econômico e tamanho de empresa, seguindo o proposto por Beck et. al. (2005), Lee et. al. (2012) e Shaffer (2002).

Para tanto, a hipótese a ser testada pode ser descrita por meio da seguinte equação:

$y_{i t}=\alpha+\beta Z_{i t 1}+V P_{i t} \gamma+\delta T F+\rho_{i t}$

(1)

onde $y_{i t}$ é a taxa de crescimento do PIB per capita, $Z_{i t 1}$ é logaritmo natural do PIB per capita, $V P_{i t}$ é um vetor de variáveis padrão utilizadas em equações de crescimento econômico, neste caso referese à taxa de crescimento populacional e aos anos médios de estudo, $T F$ é a variável que indica o tamanho da empresa e $\rho_{i t}$ é um termo de erro.

Inicialmente, a equação foi estimada por meio de system GMM (Blundell e Bond, 1998 e Arellano Bover, 1995), com o intuito de minimizar o problema de endogeneidade possivelmente presente em equações de crescimento econômico. Esses métodos utilizam variáveis instrumentais para corrigir esse problema, obtendo componentes exógenos por meio das variáveis independentes.
4 Para uma revisão sobre a relação entre tamanho da firma e potencial exportador, veja também Silva (2012). 
De acordo com Bond et al (2001), no system GMM, estima-se um sistema de equações em primeira diferença e em nível, na qual os instrumentos utilizados nas equações em nível são as variáveis defasadas em primeira diferença da série. Dessa forma, a estimação por meio de um sistema de duas equações faz com que o estimador reduza o viés e seja mais eficiente que o estimador difference GMM.

Essa metodologia, no entanto, não considera os efeitos da presença de spillovers geográficos no crescimento econômico das regiões, podendo, assim, incorrer em problemas econométricos (Badinger et. al., 2004; Ertur e Koch, 2007; Mohl e Hagen, 2010).

De acordo com Dall'erba e LeGallo (2008), são três os motivos pelos quais deve-se incorporar os efeitos espaciais em modelos de crescimento. Em primeiro lugar, do ponto de vista econométrico, uma das hipóteses de estimações de MQO está baseada na independência dos termos de erro e a violação deste pressuposto leva a estimativas e inferências não confiáveis. Segundo, permite a captura de efeitos de transbordamento geográficos entre as regiões. Em terceiro lugar, defasagens espaciais da variável dependente podem atuar como variáveis dependentes defasadas para explicar variáveis omitidas.

De modo a controlar os efeitos da dependência espacial, LeSage e Pace (2009) abordam três modelos como sendo os mais frequentemente utilizados: SEM (spatial error model), SAR (spatial autoregressive) e SDM (spatial durbin model).

O modelo SEM (spatial error model) modela a dependência espacial através do termo de erro, podendo ser descrito por meio da seguinte equação:

$$
\begin{gathered}
y_{i t}=\alpha+\beta Z_{i t-1}+\gamma V P_{i t}+\delta T F \\
+\delta_{i t}
\end{gathered}
$$

$\delta_{i t}=\theta \sum_{j=1}^{N} w_{i j} \delta_{j t}+\varepsilon_{i t}$

onde as variáveis são as mesmas utilizadas na equação 1, com exceção ao termo de erro $\delta_{i t}$, que, através do termo $w_{i j}$ contém informações a respeito da estrutura espacial e conectividade entre as regiões i e $j, \theta$ é o coeficiente de erro espacial e $\varepsilon \sim N\left(0, \sigma^{2}, I_{n}\right)$. Essa especificação indica que um choque aleatório introduzido em uma região afeta todas as regiões por meio da estrutura espacial.

No modelo SAR (spatial autoregressive), a dependência espacial é incluída no modelo por meio dos valores defasados espacialmente da variável dependente, como descrito na equação 3 .

$$
\begin{gathered}
y_{i t}=\vartheta \sum_{j=1}^{N} w_{i j} y_{j t}-\beta Z_{i t-1}+V P_{i t} \gamma+\delta G E \\
+\rho_{i t}
\end{gathered}
$$

onde $\vartheta \quad$ representa o parâmetro espacial autoregressivo e as demais variáveis são as mesmas utilizadas na equação 2 . 
De acordo com LeSage e Pace (2009), o defasamento espacial utilizado no modelo SAR pode ser usado de modo a gerar uma extensão do modelo conhecida com SDM (spatial durbin model). Esse modelo inclui defasamentos espaciais da variável dependente e das variáveis independentes, o que permite obter externalidades e spillovers advindos de diferentes fontes. O SDM é estimado a partir da seguinte equação:

$$
\begin{gathered}
y_{i t}=\vartheta \sum_{j=1}^{N} w_{i j} y_{j t}-\beta_{1} Z_{i t-1}+\beta_{2} \sum_{j=1}^{N} w_{i j} Z_{j t-1}+\gamma_{1} V P_{i t}+\gamma_{2} \sum_{j=1}^{N} w_{i j} V P_{j t}+\delta_{1} T F_{i t} \\
+\delta_{2} \sum_{j=1}^{N} w_{i j} T F_{j t} \\
+\rho_{i t}
\end{gathered}
$$

onde $w_{i j} Z_{j t-1}, w_{i j} V P_{j t}$ e $w_{i j} T F_{j t}$ são a variáveis defasadas espacialmente do logaritmo natural do PIB per capita defasado, do vetor de variáveis utilizadas em equações de crescimento econômico e da a variável que indica tamanho da empresa, respectivamente. As demais variáveis já foram descritas na equação 1.

Estimações desses modelos por meio de MQO são inapropriadas, pois, no modelo SEM, os parâmetros serão ineficientes devido à estrutura não ortogonal do termo de erro, enquanto que, no modelo SAR, as estimações via MQO geram resultados viesados e inconsistentes devido à simultaneidade na natureza da autocorrelação espacial causada pela introdução da defasagem espacial. Dessa forma, a estimação mais apropriada para esses modelos é a baseada em máxima verossimilhança ou variáveis instrumentais (Anselin, 1988).

Mais recentemente, Elhortst (2010) propôs que a estimação desses modelos por meio de dados em painel é preferível à cross-section, pois um painel de dados geralmente contém mais informações, maior variação e menos colinearidade entre as variáveis, além de gerar estimações mais eficientes. Além do mais, a literatura aponta que a modelagem espacial permite analisar os efeitos de transbordamento e a relação entre crescimento econômico e tamanho de empresas (Bruce et. al., 2009; Cravo et. al., 2014; Komarek and Loveridge, 2015). Diante dessas vantagens, um painel espacial será utilizado para estimar os três modelos anteriormente descritos.

\subsection{Análise exploratória de dados espaciais}

A presença de heterogeneidade espacial será testada por meio da análise exploratória de dados espaciais (ESDA), mostrando se os parâmetros utilizados na análise são ou não constantes no espaço.

Ertur et. al. (2006) mostra que a presença de heterogeneidade espacial e uma consequente identificação de regimes espaciais podem ser obtidas por meio da análise exploratória de dados espaciais (ESDA). Para tanto, utiliza-se o logaritmo natural da renda per capita no período inicial para verificar a existência de diferentes regimes espaciais. 
O I de Moran local permite identificar diferentes padrões de distribuição espacial. Seguindo Anselin (1995), a medida de associação espacial local (LISA), é calculada da seguinte forma:

$=\frac{y_{j} \sum_{j=1}^{n} w_{i j} y_{i}}{\sum_{i=1}^{n} y_{i}^{2}}$

onde $n$ indica o número de regiões, $w_{i j}$ são os elementos da matriz de pesos espaciais, $y_{i}$ e $y_{j}$ são os valores da variável utilizada, enquanto i e j referem-se às diferentes regiões.

Os resultados encontrados a partir da aplicação desse índice mostram dois tipos possíveis de clusters (aglomeração) ou outliers, indicando, assim, que as regiões podem apresentar dois padrões distintos ou semelhantes, de acordo com a variável utilizada.

\subsection{Dados e matrizes de pesos espaciais}

O objeto de análise deste estudo são as 558 microrregiões do Brasil. Essas regiões referem-se a grupos de municípios com características similares, tanto econômicas quanto geográficas. Segundo Cravo (2010), as microrregiões disponibilizam um grande número de observações e reduzem as distorções observadas em nível municipal.

Para se alcançar os objetivos propostos inicialmente, são utilizadas informações oriundas de diferentes bases estatísticas referentes ao período 1999 a 2009, subdividindo-os em cinco subperíodos: 1999-2001, 2001-2003, 2003-2005, 2005-2007 e 2007-200951.

Por meio de dados disponibilizados pela Relação Anual de Informação Sociais - RAIS, pode-se calcular as variáveis que indicam tamanho da empresa e uma proxi para escolaridade.

A variável de grande empresa é obtida calculando a razão entre a quantidade de vínculos ativos nos grandes estabelecimentos industriais e a quantidade de vínculos ativos no total do emprego industrial. Duas definições de grande empresa são utilizadas, mais de 500 e mais de 250 vínculos ativos.

Para a obtenção da variável micro e pequena empresa. o cálculo é similar ao da variável grande empresa. A mudança ocorre no numerador. Nessa variável, o numerador é constituído pela quantidade de vínculos ativos nos micro e pequenos ${ }^{62}$ estabelecimentos industriais.

A variável que indica escolaridade é calculada como sendo os anos médios de estudo de todos os indivíduos inseridos no setor formal. A utilização de tal proxi deve-se ao fato de não haver dados de anos médios de estudo para toda a população em nível de microrregião para os anos analisados neste estudo.

\footnotetext{
${ }^{1}$ A divisão em cinco subperíodos deve-se ao fato de que, para fazer estimativas de crescimento econômico por meio de dados em painel, é necessário que se divida o período de análise em subperíodos de 3 a 5 anos, de modo que os efeitos do ciclo de negócios não comprometam os resultados (Lee et al, 2012).

${ }^{2}$ Considera-se como pequena empresa aquela que possui até 99 vínculos ativos.
} 
Para o restante das variáveis analisadas, utilizou-se a base de dados do Instituto de Pesquisa Econômica Aplicada - Ipeadata e Instituto Brasileiro de Geografia e Estatística - IBGE. Obteve-se, assim, informações referentes ao PIB e à população de cada microrregião, respectivamente, para a obtenção das seguintes variáveis: taxa de crescimento do PIB per capita, logaritmo natural do PIB per capita no primeiro ano do período analisado e taxa de crescimento populacional.

Para modelar as interações espaciais, é necessário especificar de que forma as regiões que compõem a amostra se conectam, e a ferramenta utilizada para representar essa conectividade é a matriz de pesos espaciais (Ertur e Koch, 2007).

Neste trabalho, a matriz de pesos espaciais é elaborada a partir das relações de vizinhança entre as regiões inseridas na amostra. Assim, será utilizado primeiramente a matriz de contiguidade queen, na qual a regiões vizinhas são aquelas que compartilham uma fronteira física comum. Além dessa, serão utilizadas matrizes de pesos espaciais dos k-vizinhos mais próximos, como em Ertur e Koch (2007) e Mohl e Hagen (2010), que consiste em mensurar o efeito de vizinhança a partir da distância do centroide da região. Nessas matrizes, todas as microrregiões apresentam o mesmo número de vizinhos.

A escolha das matrizes encontra-se em acordo com a literatura, e o uso de diferentes matrizes pretende mitigar a arbitrariedade de escolha de matrizes, de tal modo que os resultados não sejam influenciados pela escolha de determinada matriz de vizinhança.

\section{Resultados}

\subsection{Análise exploratória dos dados}

A divisão político-administrativa do Brasil através de microrregiões subdivide o País em 558 unidades geográficas. De acordo com dados da RAIS (Gráfico 1), desse total, apenas 223 microrregiões possuíam empresas do setor industrial com mais de 500 vínculos ativos no ano de 1999. Em 2009, este número passa para 295 microrregiões com a presença de grandes empresas.

Gráfico 1. Microrregiões em empresas industriais

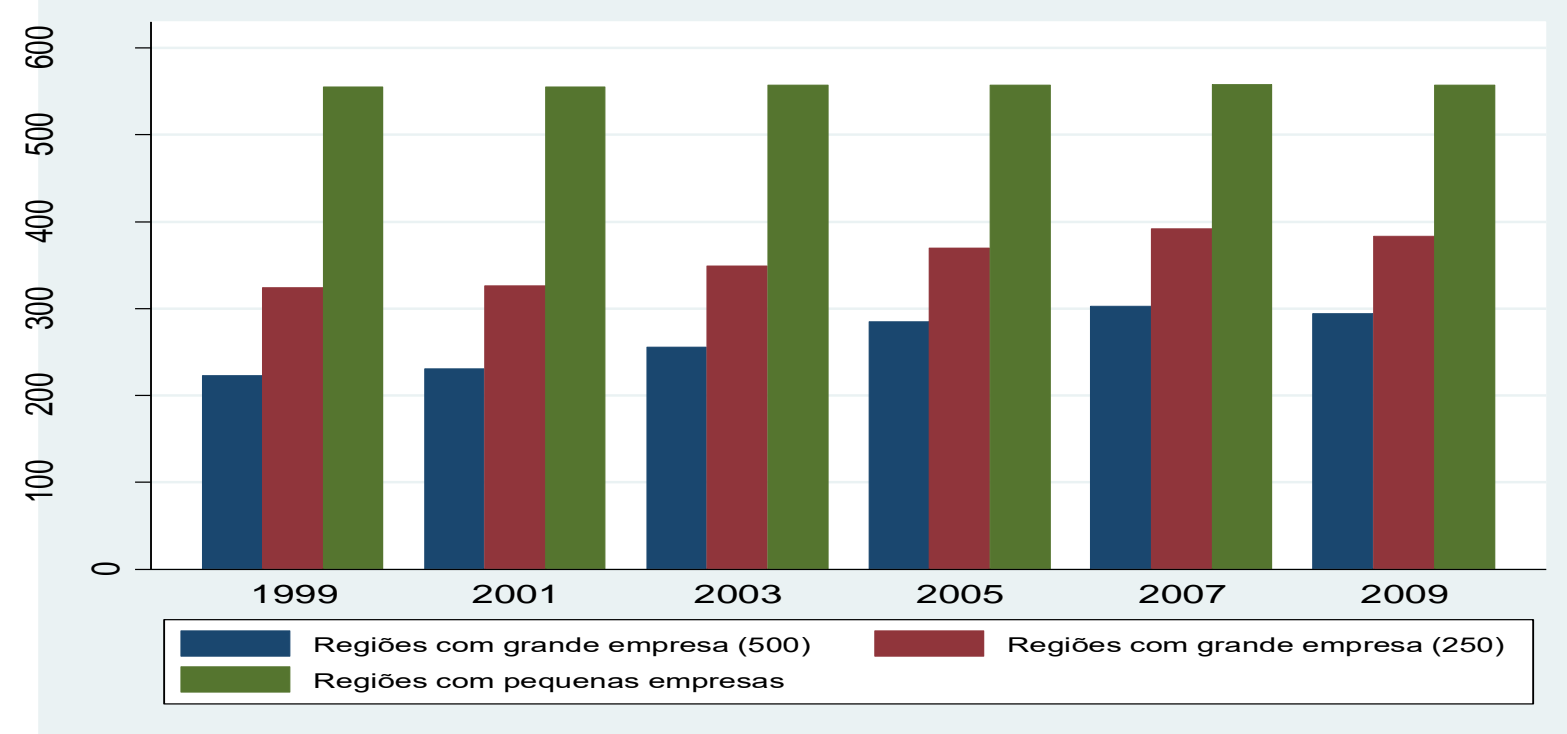


Fonte: RAIS. Elaborado pelo autor.

Ao se analisar grande empresa como sendo aquelas com mais de 250 vínculos ativos, também se percebe um aumento da presença dessas empresas nas microrregiões do País, passando de 324 para 383. Já as micro e pequenas empresas do setor industrial estão presentes na grande maioria das microrregiões, como se pode verificar no gráfico acima.

A análise da porcentagem do emprego por tamanho de empresa (Gráfico 2) mostra uma tendência de queda do emprego nas pequenas empresas do setor industrial, pois sua participação no total do emprego industrial diminuiu de $44,61 \%$, em 1999, para 42,22\%, no último período analisado. Enquanto que nas grandes empresas - com mais de 500 vínculos ativos - a porcentagem de emprego aumentou durante o período estudado, passando de $26 \%$, em 1999 , para pouco mais de $32 \%$, em 2009.

O gráfico 2 apresenta ainda uma linha indicando a diferença entre o percentual de emprego nas pequenas empresas e percentual de emprego nas grandes empresas, essa diferença apresenta tendência de queda ao longo do período analisado. A diferença que era cerca de 20 pontos percentuais no início do período diminuiu para pouco mais de 10 pontos percentuais.

\section{Gráfico 2. Percentual do emprego em grandes (500) e pequenas empresas}

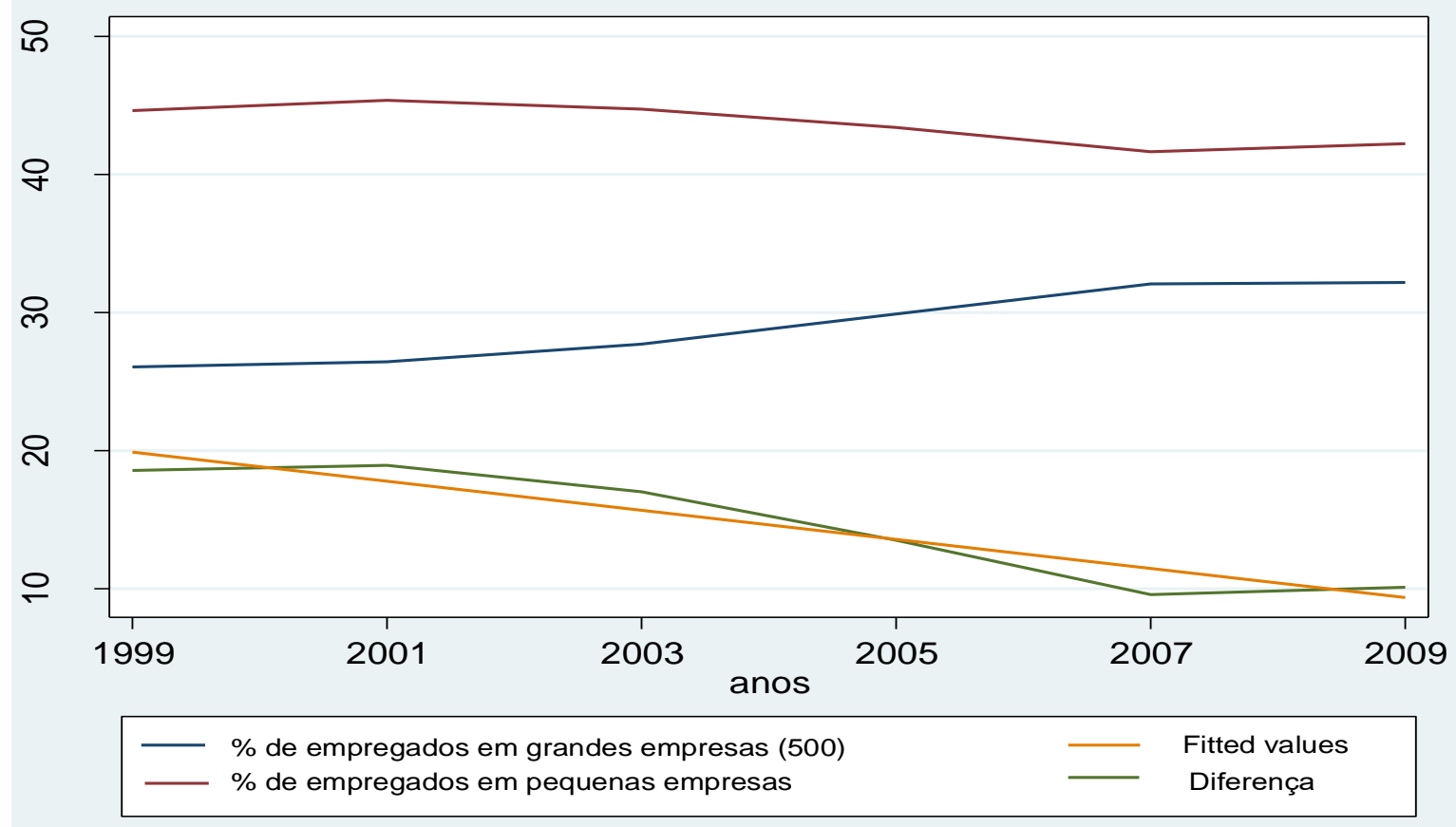

Fonte: RAIS. Elaborado pelo autor.

Ao considerar grande empresa aquela com mais de 250 vínculos ativos, também se verifica uma tendência de alta do emprego nessas empresas. No entanto, nota-se que, nos últimos anos da análise a maior parte do emprego industrial está concentrada nas grandes empresas, e não mais nas pequenas (Gráfico 3). No ano de 2009, cerca de $43 \%$ do total do emprego industrial está nas grandes empresas, ao passo que as pequenas empresas detêm $42 \%$ do emprego. 
A linha que representa a diferença no percentual do emprego entre pequenas e grandes empresas, em um primeiro momento, apresenta valores positivos para essa diferença, mas, nos últimos períodos, apresentou valores negativos, pois nesses períodos a maior parte do emprego está concentrada nas grandes empresas e não mais nas pequenas.

De maneira geral, resultados mostram um crescimento do emprego industrial nas grandes empresas, com ambas as definições de grande empresa, e uma queda na participação do total do emprego industrial por parte das pequenas empresas. Apesar da verificada importância das grandes empresas no Brasil, pouco se tem estudado a respeito de seus impactos no crescimento econômico, especialmente em nível regional.

Diante disso, as próximas seções têm como objetivo preencher essa lacuna existente na literatura e apresentar resultados empíricos que demostrem qual a relação existente entre tamanho de empresa e crescimento econômico em nível regional.

\section{Gráfico 3. Percentual do emprego em grandes (250) e pequenas empresas}

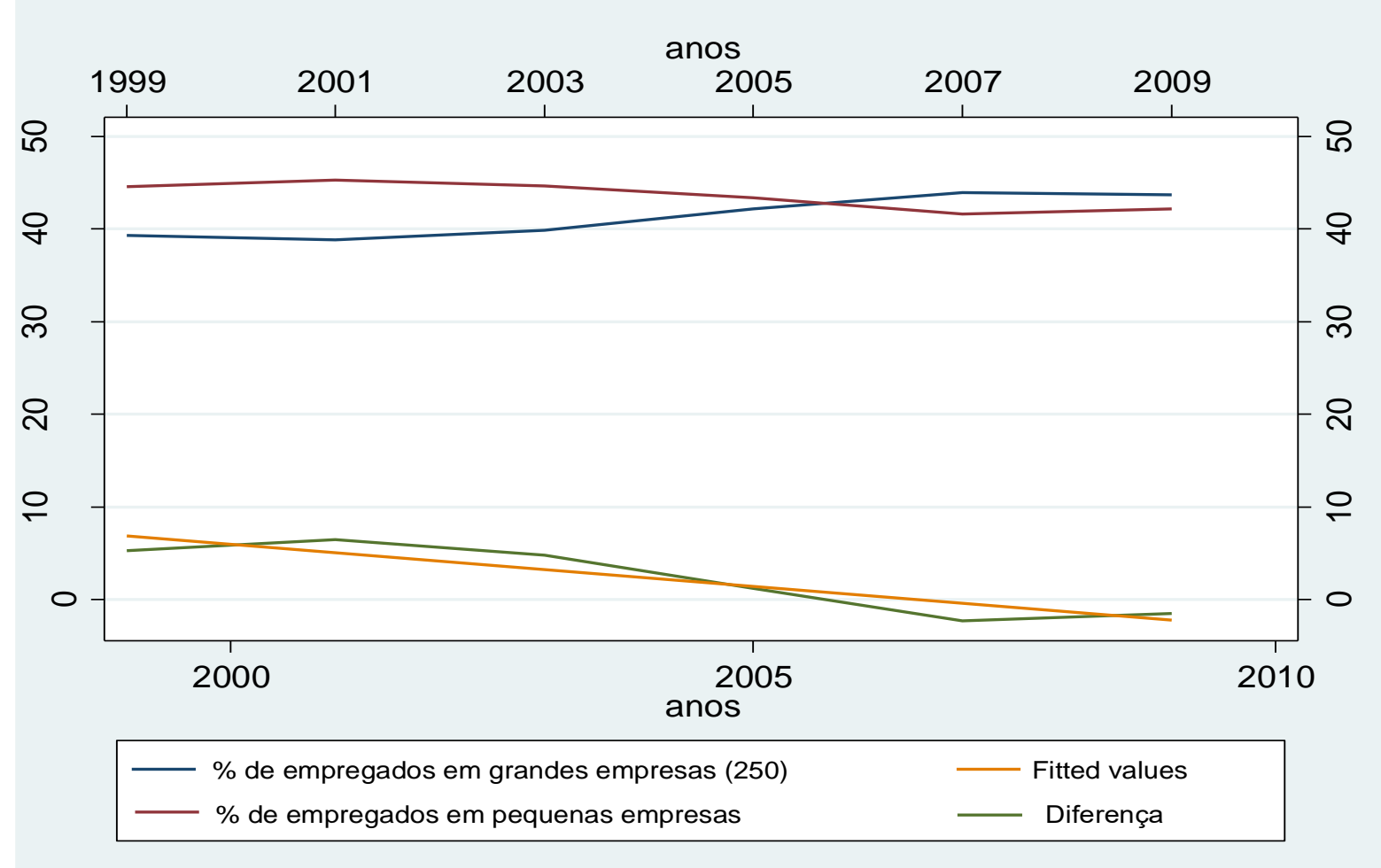

Fonte: RAIS. Elaborado pelo autor.

\subsection{Resultados das estimações via system GMM}

Os resultados obtidos pelas estimações por meio de system GMM (Tabela 1) estão subdivididos em três modelos. O modelo 1 indica o impacto da presença de grandes empresas no crescimento econômico das microrregiões, utilizando como variável de grande empresa aquelas com mais de 500 vínculos ativos. No modelo 2, são consideradas grandes empresas aquelas com mais de 250 indivíduos 
empregados. O modelo 3 mostra a relação existente entre pequenas empresas e crescimento econômico das microrregiões.

Nos modelos 1 e 2, os resultados indicam um sinal positivo e estatisticamente significante para a variável de grande empresa, sendo que as grandes empresas com mais 250 vínculos ativos apresentaram um coeficiente de explicação com maior magnitude. Dessa forma, pode-se inferir que a presença de grandes empresas do setor industrial contribui positivamente para o crescimento do PIB per capita das microrregiões. Tal resultado vai ao encontro dos fatos observados por Lee et. al. (2012), onde a presença de grandes empresas promove o crescimento do PIB per capita dos países analisados.

O sinal negativo da variável defasada do logaritmo natural do PIB per capita, vai ao encontro dos modelos de crescimento neoclássico. Tal resultado indica um processo de convergência, no qual as regiões com nível de renda per capita inicial menor tendem a crescer mais rapidamente que aquelas onde o nível de renda inicial é mais elevado.

O sinal positivo da variável associada ao capital humano indica que quanto mais elevado o nível de escolaridade da população, mais elevado tende a ser o crescimento econômico da região na qual esta população está inserida.

Tabela 1. Resultados das estimações via system GMM para todas as Microrregiões

\begin{tabular}{|c|c|c|c|c|c|c|}
\hline \multirow{2}{*}{$\begin{array}{l}\text { Microrregiões } \\
\text { Estimação }\end{array}$} & \multicolumn{6}{|c|}{ System GMM } \\
\hline & one-step & two-step & one-step & two-step & one-step & two-step \\
\hline \multirow[t]{2}{*}{ LN PIB per capita defasada } & -0.111 & -0.087 & -0.103 & -0.082 & -0.096 & -0.097 \\
\hline & $(-3.78)^{* * * *}$ & $(-2.90)^{* * * *}$ & $(-3.64)^{* * * *}$ & $(-2.97)^{* * * *}$ & $(-3.47)^{* * * *}$ & $(-3.27)^{* * * *}$ \\
\hline \multirow{2}{*}{ Escolaridade } & 0.016 & 0.014 & 0.014 & 0.011 & 0.041 & 0.043 \\
\hline & $(3.31)^{* * * *}$ & $(2.78) * * *$ & $(2.82)^{* * *}$ & $(2.28) * *$ & $(4.09) * * *$ & $(4.13)^{* * *}$ \\
\hline \multirow{2}{*}{ Tx de crescimento populacional } & 0.053 & $(0.170)$ & -0.045 & 0.110 & -0.446 & -0.605 \\
\hline & $(0.12)$ & 0.45 & $(-0.10)$ & $(0.26)$ & $(-0.95)$ & $(-1.45)$ \\
\hline \multirow{2}{*}{ Grande empresa (500) } & 0.256 & $(0.168)$ & & & & \\
\hline & $(3.86)^{* * * *}$ & $(2.41)^{* *}$ & & & & \\
\hline \multirow{2}{*}{ Grande empresa (250) } & & & 0.220 & 0.171 & & \\
\hline & & & $(3.14)^{* * *}$ & $(2.43)^{* *}$ & & \\
\hline Pequena empresa & & & & & -0.259 & -0.261 \\
\hline & & & & & $(-3.39)^{* * * *}$ & $(-3.52)^{* * * *}$ \\
\hline Observações & 2784 & 2784 & 2784 & 2784 & 2784 & 2784 \\
\hline Número de microrregiōes & 558 & 558 & 558 & 558 & 558 & 558 \\
\hline Teste AR(2) & 0.16 & 0.140 & 0.121 & 0.124 & 0.106 & 0.104 \\
\hline Teste de Hansen & 0.000 & 0.000 & 0.000 & 0.000 & 0.000 & 0.000 \\
\hline
\end{tabular}

Nota: os números em parênteses são as estatísticas t. ***, **, * indicam que os parâmetros estimados são significativamente diferentes de zero ao nível de 1, 5 e 10\%. Fonte: IBGE, IPEADATA e RAIS. Elaborado pelos autores.

Os resultados encontrados no terceiro modelo mostram um efeito negativo e significativo das pequenas empresas industriais no crescimento, sugerindo, assim, que essas empresas não contribuem para acelerar o crescimento econômico das microrregiões. A relação negativa entre pequena empresa e crescimento 
econômico encontrada neste trabalho vai ao encontro dos resultados obtidos por Cravo et. al. (2010) e Cravo (2010).

O p-valor do teste AR (2) para todas as estimações indica que não há endogeneidade proveniente de autocorrelação serial. Por outro lado, o $p$-valor do teste de Hansen aponta para a presença de endogeneidade, indicando, assim, que através das estimações de system GMM não foi possível encontrar variáveis exógenas capazes de mitigar esse problema.

\subsection{Análise espacial}

\subsubsection{Dependência espacial}

Nessa seção, estão reportados os resultados encontrados a partir das estimações de painel espacial com efeitos fixos, utilizando matriz ${ }^{3}$ de contiguidade Queen de primeira ordem (Tabela 2). Os resultados se mostraram similares em todos os três modelos estimados e com as diferentes matrizes de pesos espaciais utilizadas, só alterando a magnitude dos coeficientes, mas permanecendo iguais as relações entre as variáveis independentes e a variável dependente.

A estimação por meio do modelo SDM apresenta resultados que são interpretados de maneira diferente dos dois modelos também estimados SEM e SAR. Isso se deve ao fato de que os coeficientes das variáveis independentes representam o efeito direto na variável dependente, enquanto que os coeficientes das variáveis independentes defasadas espacialmente capturam os efeitos espaciais dessas variáveis na variável dependente.

3 Também foram obtidos resultados utilizando a matriz de pesos espaciais k-vizinhos mais próximos ( $k=5$ ), e estes se encontram no apêndice A (Tabela A.1) deste artigo. 
Tabela 2. Resultados dos modelos de painel espacial

\begin{tabular}{|c|c|c|c|c|c|c|c|c|c|}
\hline \multirow{2}{*}{$\begin{array}{l}\text { Microrregiões } \\
\text { Estimação } \\
\end{array}$} & \multirow{2}{*}{\multicolumn{3}{|c|}{ SEM }} & \multirow{2}{*}{\multicolumn{3}{|c|}{ SAR }} & \multirow{2}{*}{\multicolumn{3}{|c|}{ SDM }} \\
\hline & & & & & & & & & \\
\hline $\begin{array}{c}\text { LN PIB per capita } \\
\text { defasada }\end{array}$ & $\begin{array}{c}-0.67 \\
(-38.81)^{* * *}\end{array}$ & $\begin{array}{c}-0.67 \\
(-38.9)^{* * *}\end{array}$ & $\begin{array}{c}-0.67 \\
(-38.88)^{* * *}\end{array}$ & $\begin{array}{c}-0.64 \\
(-37.94)^{* * *}\end{array}$ & $\begin{array}{c}-0.64 \\
(-38.04)^{* * *}\end{array}$ & $\begin{array}{c}-0.65 \\
(-38.07)^{* * *}\end{array}$ & $\begin{array}{c}-0.66 \\
(-38.37)^{* * *}\end{array}$ & $\begin{array}{c}-0.66 \\
(-38.45)^{* * *}\end{array}$ & $\begin{array}{c}-0.67 \\
(-38.53)^{* * *}\end{array}$ \\
\hline Escolaridade & $\begin{array}{c}-0.01 \\
(-1.28)\end{array}$ & $\begin{array}{c}-0.01 \\
(-1.26)\end{array}$ & $\begin{array}{l}-0.01 \\
(-1.4)\end{array}$ & $\begin{array}{c}0.00 \\
(-0.73)\end{array}$ & $\begin{array}{c}0.00 \\
(-0.72)\end{array}$ & $\begin{array}{c}0.00 \\
(-0.87)\end{array}$ & $\begin{array}{c}-0.01 \\
(-1.26)\end{array}$ & $\begin{array}{c}-0.01 \\
(-1.25)\end{array}$ & $\begin{array}{c}-0.01 \\
(-1.35)\end{array}$ \\
\hline $\begin{array}{l}\text { Tx de crescimento } \\
\text { populacional }\end{array}$ & $\begin{array}{c}-0.43 \\
(-9.18)^{* * *}\end{array}$ & $\begin{array}{c}-0.43 \\
\left.(-9.22)^{* *}\right)\end{array}$ & $\begin{array}{c}-0.44 \\
(-9.23) * * *\end{array}$ & $\begin{array}{c}-0.42 \\
(-8.91)^{* * *}\end{array}$ & $\begin{array}{c}-0.42 \\
(-8.96)^{* * *}\end{array}$ & $\begin{array}{c}-0.42 \\
(-9.00)^{* * *}\end{array}$ & $\begin{array}{c}-0.43 \\
(-9.12)^{* * * *}\end{array}$ & $\begin{array}{c}-0.43 \\
(-9.16)^{* * *}\end{array}$ & $\begin{array}{c}-0.44 \\
(-9.25)^{* * *}\end{array}$ \\
\hline Grande empresa (500) & $\begin{array}{c}0.02 \\
-1.10\end{array}$ & & & $\begin{array}{c}0.02 \\
(-1.22)\end{array}$ & & & $\begin{array}{c}0.02 \\
(-1.12)\end{array}$ & & \\
\hline Grande empresa (250) & & $\begin{array}{c}0.04 \\
(2.29)^{* *}\end{array}$ & & & $\begin{array}{c}0.04 \\
(2.48)^{* *}\end{array}$ & & & $\begin{array}{c}0.04 \\
(2.32)^{* *}\end{array}$ & \\
\hline Pequena empresa & & & $\begin{array}{c}-0.03 \\
(-2.17)^{* *}\end{array}$ & & & $\begin{array}{c}-0.04 \\
(-2.82)^{* * *}\end{array}$ & & & $\begin{array}{c}-0.04 \\
(-2.56)^{* *}\end{array}$ \\
\hline $\begin{array}{c}\text { W*LN PIB per capita } \\
\text { defasada }\end{array}$ & & & & & & & $\begin{array}{c}0.16 \\
(4.74)^{* * * *}\end{array}$ & $\begin{array}{c}0.16 \\
(4.69)^{* * * *}\end{array}$ & $\begin{array}{c}0.15 \\
(4.26)^{* * * *}\end{array}$ \\
\hline $\mathrm{W}^{*}$ Escolaridade & & & & & & & $\begin{array}{c}0.02 \\
(2.32)^{* *}\end{array}$ & $\begin{array}{c}0.02 \\
(2.3)^{* * *}\end{array}$ & $\begin{array}{c}0.02 \\
(2.34)^{* *}\end{array}$ \\
\hline $\begin{array}{c}\mathrm{W} * \mathrm{Tx} \text { de crescimento } \\
\text { populacional }\end{array}$ & & & & & & & $\begin{array}{c}0.21 \\
(2.25)^{* * *}\end{array}$ & $\begin{array}{c}0.21 \\
(2.22) * *\end{array}$ & $\begin{array}{c}0.20 \\
(2.13)^{* *}\end{array}$ \\
\hline $\begin{array}{c}\mathrm{W} * \text { Grande empresa } \\
(500)\end{array}$ & & & & & & & $\begin{array}{c}0.01 \\
(-0.18)\end{array}$ & & \\
\hline $\begin{array}{c}\mathrm{W} * \text { Grande empresa } \\
(250)\end{array}$ & & & & & & & & $\begin{array}{c}0.01 \\
(-0.2)\end{array}$ & \\
\hline $\mathrm{W} *$ Pequena empresa & & & & & & & & & $\begin{array}{c}-0.07 \\
(-2.21)^{* *}\end{array}$ \\
\hline Parâmetro espacial $(\lambda)$ & $\begin{array}{c}0.32446 \\
(13.67)^{* * * *}\end{array}$ & $\begin{array}{c}0.32422 \\
(13.65)^{* * * *}\end{array}$ & $\begin{array}{c}0.32210 \\
(13.52)^{* * * *}\end{array}$ & & & & & & \\
\hline Parâmetro espacial $(\rho)$ & & & & $\begin{array}{c}0.24729 \\
(12.01)^{* * *}\end{array}$ & $\begin{array}{c}0.24639 \\
(11.96)^{* * *}\end{array}$ & $\begin{array}{l}0.24731 \\
(12)^{* * * *}\end{array}$ & $\begin{array}{c}0.31499 \\
(13.19)^{* * *}\end{array}$ & $\begin{array}{c}0.31445 \\
(13.15)^{* * *}\end{array}$ & $\begin{array}{c}0.30765 \\
(12.8)^{* * *}\end{array}$ \\
\hline Observações & 2790 & 2790 & 2790 & 2790 & 2790 & 2790 & 2790 & 2790 & 2790.00 \\
\hline Log-likelihood (LIK) & 12. 8221 & 12. 8221 & 12. 8221 & 12. 8221 & 12. 8221 & 12. 8221 & 12. 8221 & 12. 8221 & 12. 8221 \\
\hline
\end{tabular}

Nota: os números em parênteses são as estatísticas t. ***, **, * indicam que os parâmetros estimados são significativamente diferentes de zero ao nível de 1, 5 e 10\%.

Fonte: IBGE, IPEADATA e RAIS. Elaborado pelos autores.

Os parâmetros espaciais $\lambda$ e $\rho$, que demostram a dependência espacial da variável dependente, apresentaram valores positivos e significativos em todas as estimações. Isso indica que a estrutura espacial tem influência na trajetória da taxa de crescimento do PIB per capita e que, negligenciar a dependência espacial, pode gerar viés de variável omitida e levar a estimadores inconsistentes.

Os resultados encontrados na estimação SDM mostram que a renda per capita é negativamente relacionada com o crescimento, indicando um processo de convergência de renda. Já a defasagem espacial dessa variável apresentou coeficiente positivo e significativo, mostrando, assim, que regiões que possuem elevado PIB per capita impactam positivamente no crescimento econômico da região vizinha.

O coeficiente da variável taxa de crescimento populacional se mostrou negativo e significativo, o que indica que uma elevada taxa de crescimento populacional impacta negativamente no crescimento do PIB per capita. Já a defasagem espacial da taxa de crescimento populacional, por sua vez, apresentou um coeficiente positivo e significativo, sugerindo, assim, que a taxa de crescimento 
do PIB per capita dentro de uma microrregião é positivamente influenciado pelo crescimento populacional dos seus vizinhos.

A variável associada ao capital humano apresentou sinal negativo e significância estatística somente quando da utilização da matriz de pesos espaciais k-vizinhos (5). No entanto, essa variável defasada espacialmente apresentou coeficiente positivo e significativo, indicando, assim, que os níveis de educação mais elevados das regiões vizinhas são benéficos para o crescimento econômico da microrregião.

Para as variáveis associadas à grande empresa, os resultados mostram um sinal positivo para ambas as definições de grande empresa, e estatisticamente significante somente para aquela em que a definição é mais de 250 vínculos ativos. Dessa forma, pode-se inferir que a presença de grandes empresas do setor industrial interfere positivamente na taxa de crescimento do PIB per capita das microrregiões.

Os resultados relativos à defasagem espacial das variáveis de grande empresa também apresentaram sinal positivo, no entanto não apresentaram significância estatística. Dessa forma, não pode fazer inferência a respeito do impacto da presença de grandes empresas das regióes vizinhas na taxa de crescimento econômico.

Ao se inserir a variável referente às pequenas empresas, os resultados mostram um efeito negativo e significativo das pequenas empresas industriais no crescimento do PIB per capita. Tal resultado indica que, nas regiões onde a presença de pequenas empresas do setor industrial é mais elevada, a taxa de crescimento do PIB per capita é menor. Já os resultados dessa variável defasada espacialmente mostraram sinal negativo e com significância estatística, o que sugere uma relação negativa entre pequenas empresas nas regiões vizinhas e taxa de crescimento do PIB per capita.

As estimações utilizando os modelos SEM e SAR apresentaram resultados similares aos descritos anteriormente. Esses dois modelos mostram que ao se controlar a dependência espacial tanto pelo termo de erro como pelos valores defasados espacialmente da variável dependente, a relação encontrada entre grandes empresas e crescimento econômico permanece positiva, enquanto que relação entre pequenas empresas e crescimento econômico se mostrou negativa.

A utilização desses modelos de dependência espacial dão sustentação e maior robustez aos resultados encontrados nas estimações de GMM. Confirmando, assim, que, durante o período analisado, as grandes empresas industriais foram mais importantes para o crescimento do PIB per capita das microrregiões brasileiras que as pequenas empresas.

\subsubsection{Heterogeneidade espacial}

A literatura aponta que existem diferentes dinâmicas produtivas e econômicas entre as microrregiões brasileiras, associadas a níveis de desenvolvimento também distintos, formando, assim, regimes espaciais diferentes (Cravo et al., 2014; Laurini et al., 2005; Silveira-Neto e Azzoni, 2006). 
Os resultados do I de Moran local vão ao encontro da literatura e sugerem dois regimes espaciais diferentes no que tange à renda per capita (Figura 1)4: um, de renda per capita mais elevada, abrangendo as regiões Sul, Sudeste e Centro-Oeste, e outro, de renda per capita menor, relativo às regiões Norte e Nordeste do Brasil.

A constatação da existência de dois regimes espaciais diferentes no Brasil sugere que a relação entre tamanho das firmas e crescimento econômico deve ser analisada em cada regime separadamente, de modo que a relação entre variável explicada e variáveis explicativas pode ser alterada de acordo com o regime espacial.

Assim, divide-se a amostra inicial em duas, uma, que abrange as regiões Sul, Sudeste e Centro-Oeste, com 306 microrregiões, e outra, compreendendo as regiões Norte e Nordeste do Brasil, com 252 microrregiões. E estimam-se novamente os três modelos, com as diferentes matrizes de pesos espaciais. Figura 1. I de Moran local (LISA) do logaritmo natural do PIB per capita no ano
inicial

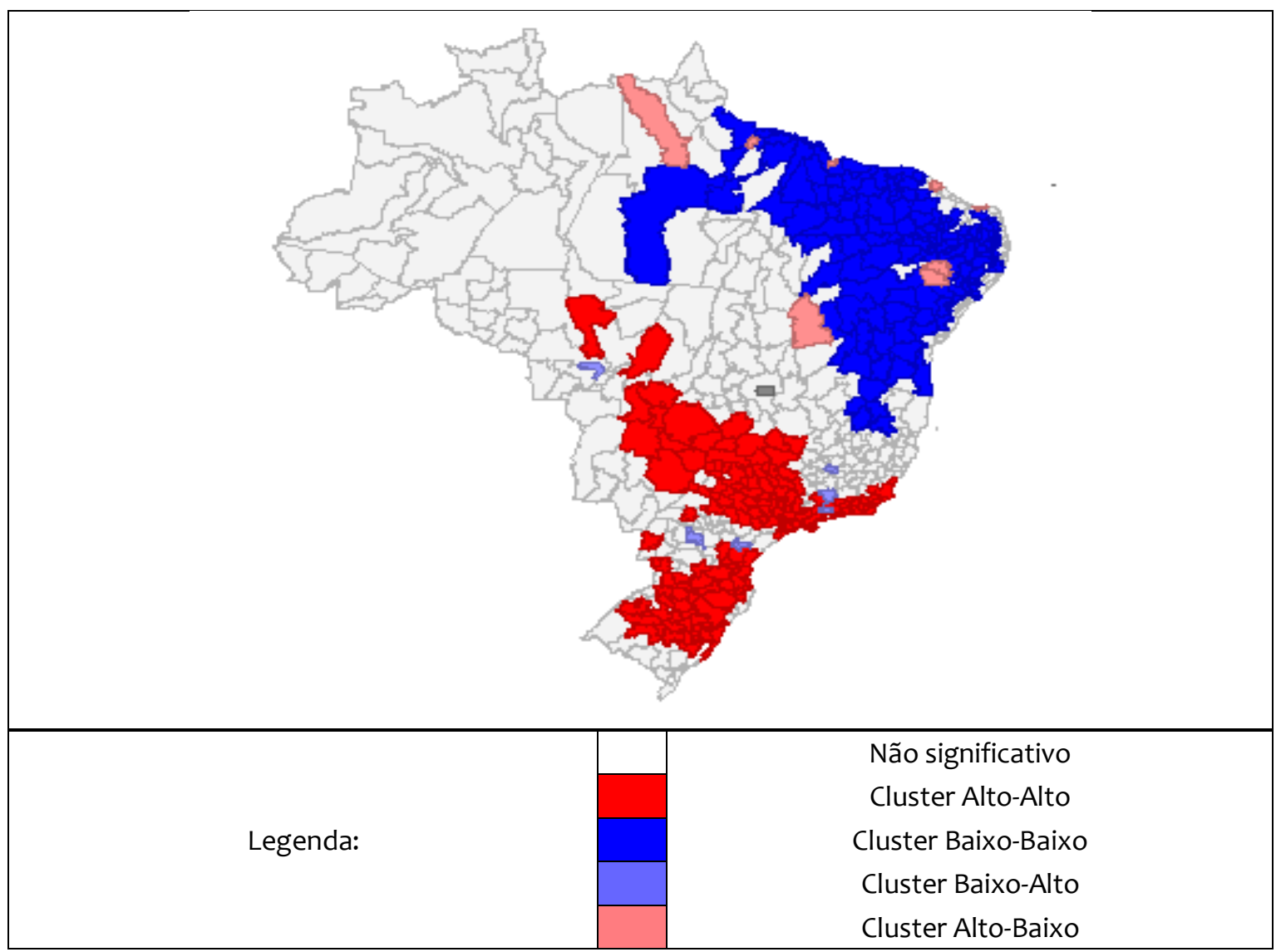

Fonte: IBGE e Ipeadata. Elaborado pelos autores.

Os resultados reportados nessa seção referem-se à matriz Queen de primeira ordem. Os resultados obtidos com a matriz k-vizinhos $(k=5)$ encontram-se no apêndice $C$ deste trabalho.

${ }^{4}$ A relação de contiguidade utilizada para a análise do I de Moran local foi a matriz de pesos espaciais Queen de primeira ordem. Outras matrizes foram também utilizadas, e os resultados destas estão no apêndice B desse artigo. 
A tabela 3 apresenta resultados que concernem às microrregiões de renda per capita mais baixa, localizadas no Norte e Nordeste do Brasil. Nessas regiões, os resultados não apontam valores significativos para os coeficientes referentes aos diferentes tamanhos de empresa. Dessa forma, não se pode fazer inferência no que diz respeito à relação entre tamanho de empresa e crescimento econômico nas microrregiões do Norte e Nordeste do País.

Nas demais variáveis, os resultados não diferem muito do encontrado para o Brasil como um todo. Chama a atenção, no entanto, o coeficiente da variável associada ao capital humano, pois a magnitude dos coeficientes aumentou com relação ao Brasil como um todo, bem como sua significância estatística, mostrando, assim, uma relação negativa entre os níveis de capital humano e a taxa de crescimento do PIB per capita.

Tabela 3. Resultados dos modelos de painel espacial para as regióes Norte e Nordeste

\begin{tabular}{|c|c|c|c|c|c|c|c|c|c|}
\hline \multirow{2}{*}{$\begin{array}{c}\text { Microrregiões } \\
\text { Estimação }\end{array}$} & & & & & & & & & \\
\hline & \multicolumn{3}{|c|}{ SEM } & \multicolumn{3}{|c|}{ SAR } & \multicolumn{3}{|c|}{ SDM } \\
\hline $\begin{array}{c}\text { LN PIB per capita } \\
\text { defasada }\end{array}$ & $\begin{array}{c}-0.6410 \\
(-24.97)^{* * * *}\end{array}$ & $\begin{array}{c}-0.6418 \\
(-25.02)^{* * * *}\end{array}$ & $\begin{array}{c}-0.6423 \\
(-24.98)^{* * * *}\end{array}$ & $\begin{array}{c}-0.6256 \\
(-24.44) * * *\end{array}$ & $\begin{array}{c}-0.6264 \\
(-24.48) * * *\end{array}$ & $\begin{array}{c}-0.6275 \\
(-24.45) * * *\end{array}$ & $\begin{array}{c}-0.6459 \\
(-25.07) * * *\end{array}$ & $\begin{array}{c}-0.6460 \\
(-25.11)^{* * * *}\end{array}$ & $\begin{array}{c}-0.6477 \\
(-25.04) * * *\end{array}$ \\
\hline Escolaridade & $\begin{array}{c}-0.0218 \\
(-3.6)^{* * * *}\end{array}$ & $\begin{array}{c}-0.0211 \\
(-3.51)^{* * *}\end{array}$ & $\begin{array}{c}-0.0218 \\
(-3.63) * * *\end{array}$ & $\begin{array}{c}-0.0225 \\
(-3.72)^{* * *}\end{array}$ & $\begin{array}{c}-0.0219 \\
(-3.63)^{* * * *}\end{array}$ & $\begin{array}{c}-0.0226 \\
(-3.76)^{* * *}\end{array}$ & $\begin{array}{c}-0.0204 \\
(-3.38)^{* * *}\end{array}$ & $\begin{array}{c}-0.0201 \\
(-3.35)^{* * *}\end{array}$ & $\begin{array}{c}-0.0205 \\
(-3.41)^{* * *}\end{array}$ \\
\hline $\begin{array}{l}\text { Tx de crescimento } \\
\text { populacional }\end{array}$ & $\begin{array}{c}-0.4213 \\
(-7.01)^{* * * *}\end{array}$ & $\begin{array}{c}-0.4220 \\
(-7.03)^{* * *}\end{array}$ & $\begin{array}{c}-0.4228 \\
(-7.03) * * *\end{array}$ & $\begin{array}{c}-0.3877 \\
(-6.47) * * *\end{array}$ & $\begin{array}{c}-0.3883 \\
(-6.48)^{* * * *}\end{array}$ & $\begin{array}{l}-0.3900 \\
(-6.5)^{* * * *}\end{array}$ & $\begin{array}{c}-0.4358 \\
(-7.23) * * *\end{array}$ & $\begin{array}{c}-0.4357 \\
(-7.24)^{* * *}\end{array}$ & $\begin{array}{c}-0.4377 \\
(-7.26)^{* * *}\end{array}$ \\
\hline Grande empresa (500) & $\begin{array}{l}-0.0004 \\
(-0.01)\end{array}$ & & & $\begin{array}{l}0.0009 \\
(0.04)\end{array}$ & & & $\begin{array}{l}0.0008 \\
(0.03)\end{array}$ & & \\
\hline Grande empresa (250) & & $\begin{array}{l}0.0330 \\
(1.57)\end{array}$ & & & $\begin{array}{l}0.0306 \\
(1.42)\end{array}$ & & & $\begin{array}{l}0.0282 \\
(1.33)\end{array}$ & \\
\hline Pequena empresa & & & $\begin{array}{l}-0.0139 \\
(-0.76)\end{array}$ & & & $\begin{array}{l}-0.0173 \\
(-0.93)\end{array}$ & & & $\begin{array}{c}-0.0134 \\
(-0.73)\end{array}$ \\
\hline $\begin{array}{c}\text { W*LN PIB per capita } \\
\text { defasada }\end{array}$ & & & & & & & $\begin{array}{c}0.1566 \\
(2.91)^{* * *}\end{array}$ & $\begin{array}{c}0.1598 \\
(2.97)^{* * *}\end{array}$ & $\begin{array}{c}0.1529 \\
(2.82)^{* * * *}\end{array}$ \\
\hline $\mathrm{W} *$ Escolaridade & & & & & & & $\begin{array}{l}-0.0046 \\
(-0.36)\end{array}$ & $\begin{array}{l}-0.0074 \\
(-0.59)\end{array}$ & $\begin{array}{c}-0.0051 \\
(-0.41)\end{array}$ \\
\hline $\mathrm{W} * \mathrm{Tx}$ de crescimento & & & & & & & 0.3341 & 0.3414 & 0.3307 \\
\hline populacional & & & & & & & $(2.77)^{* * * *}$ & $(2.83)^{* * * *}$ & $(2.74)^{* * * *}$ \\
\hline $\begin{array}{l}\mathrm{W} * \text { Grande empresa } \\
(500)\end{array}$ & & & & & & & $\begin{array}{l}0.0106 \\
(0.21)\end{array}$ & & \\
\hline $\begin{array}{c}\mathrm{W} * \text { Grande empresa } \\
(250)\end{array}$ & & & & & & & & $\begin{array}{l}-0.0562 \\
(-1.34)\end{array}$ & \\
\hline $\mathrm{W} *$ Pequena empresa & & & & & & & & & $\begin{array}{l}-0.0122 \\
(-0.32)\end{array}$ \\
\hline Parâmetro espacial $(\lambda)$ & $\begin{array}{c}0.2313 \\
(6.22)^{* * * *}\end{array}$ & $\begin{array}{c}0.2335 \\
(6.28)^{* * *}\end{array}$ & $\begin{array}{c}0.2309 \\
(6.2)^{* * *}\end{array}$ & & & & & & \\
\hline Parâmetro espacial ( $\rho$ ) & & & & $\begin{array}{c}0.1448 \\
(4.47) * * *\end{array}$ & $\begin{array}{l}0.1457 \\
(4.5)^{* * *}\end{array}$ & $\begin{array}{c}0.1451 \\
(4.49)^{* * * *}\end{array}$ & $\begin{array}{c}0.2230 \\
(6.02)^{* * *}\end{array}$ & $\begin{array}{c}0.2258 \\
(6.11)^{* * *}\end{array}$ & $\begin{array}{c}0.2221 \\
(5.99)^{* * * *}\end{array}$ \\
\hline Observações & 1260 & 1260 & 1260 & 1260 & 1260 & 1260 & 1260 & 1260 & 1260 \\
\hline Log-likelihood (LIK) & 12.8221 & 12.8221 & 12.8221 & 12.8221 & 12.8221 & 12.8221 & 12.8221 & 12.8221 & 12.8221 \\
\hline
\end{tabular}

Nota: os números em parênteses são as estatísticas $t .{ }^{* * *},{ }^{* *}$, * indicam que os parâmetros estimados são significativamente diferentes de zero ao nível de 1, 5 e 10\%.

Fonte: IBGE, Ipeadata e RAIS. Elaborado pelos autores.

Na tabela 4, encontram-se os resultados referentes às regiões Sul, Sudeste e Centro-Oeste. Para essas regiões alguns resultados diferem não só da análise anterior, mas também da análise do Brasil como um todo.

Primeiramente, nessas regiões, o tamanho das empresas tem relação estatisticamente significante com a taxa de crescimento do PIB per capita. De 
acordo com os resultados, as grandes empresas do setor industrial contribuem positivamente para o crescimento do PIB per capita das microrregiões. As pequenas empresas, por sua vez, apresentaram uma relação negativa e significativa com a variável explicada.

Com relação à variável associada ao capital humano, os coeficientes apresentaram sinais positivos e significativos, mostrando que os níveis de capital humano dessas regiões contribuem para uma maior taxa de crescimento do PIB per capita. Esse resultado difere tanto do encontrado para todo o Brasil como dos resultados referentes às regiões Norte e Nordeste. Os demais resultados são similares aos obtidos nas estimações anteriores.

Tabela 4. Resultados dos modelos de painel espacial para as regiões Sul, Sudeste e Centro-Oeste

\begin{tabular}{|c|c|c|c|c|c|c|c|c|c|}
\hline Microrregiões & & & & & & & & & \\
\hline Estimação & & SEM & & & SAR & & & SDM & \\
\hline $\begin{array}{c}\text { LN PIB per capita } \\
\text { defasada }\end{array}$ & $\begin{array}{c}-0.7033 \\
(-30.05)^{* * * *}\end{array}$ & $\begin{array}{c}-0.7028 \\
(-29.97)^{* * * *}\end{array}$ & $\begin{array}{l}-0.7076 \\
-30.1900\end{array}$ & $\begin{array}{c}-0.6767 \\
(-29.79) * * *\end{array}$ & $\begin{array}{c}-0.6768 \\
(-29.74) * * *\end{array}$ & $\begin{array}{c}-0.6828 \\
(-30.02)^{* * * *}\end{array}$ & $\begin{array}{c}-0.6983 \\
(-29.66)^{* * * *}\end{array}$ & $\begin{array}{c}-0.6968 \\
(-29.56) * * *\end{array}$ & $\begin{array}{c}-0.7013 \\
(-29.84)^{* * * *}\end{array}$ \\
\hline Escolaridade & $\begin{array}{c}0.0330 \\
(2.91)^{* * * *}\end{array}$ & $\begin{array}{l}0.0316 \\
(2.8)^{* * * *}\end{array}$ & $\begin{array}{c}0.0321 \\
(2.85)^{* * * *}\end{array}$ & $\begin{array}{c}0.0394 \\
(3.56)^{* * *}\end{array}$ & $\begin{array}{c}0.0380 \\
(3.45)^{* * *}\end{array}$ & $\begin{array}{c}0.0388 \\
(3.54) * * *\end{array}$ & $\begin{array}{c}0.0330 \\
(2.93)^{* * * *}\end{array}$ & $\begin{array}{c}0.0313 \\
(2.79)^{* * * *}\end{array}$ & $\begin{array}{c}0.0328 \\
(2.94)^{* * *}\end{array}$ \\
\hline $\begin{array}{l}\text { Tx de crescimento } \\
\text { populacional }\end{array}$ & $\begin{array}{c}-0.4189 \\
(-5.49)^{* * *}\end{array}$ & $\begin{array}{c}-0.4249 \\
(-5.56)^{* * *}\end{array}$ & $\begin{array}{c}-0.4232 \\
(-5.55) * * *\end{array}$ & $\begin{array}{c}-0.4816 \\
(-6.35)^{* * * *}\end{array}$ & $\begin{array}{l}-0.4862 \\
(-6.4)^{* * * *}\end{array}$ & $\begin{array}{c}-0.4816 \\
(-6.36) * * *\end{array}$ & $\begin{array}{c}-0.4480 \\
(-5.88) * * *\end{array}$ & $\begin{array}{c}-0.4565 \\
(-5.99) * * *\end{array}$ & $\begin{array}{c}-0.4543 \\
(-5.99)^{* * *}\end{array}$ \\
\hline Grande empresa (500) & $\begin{array}{c}0.0534 \\
(1.98)^{* *}\end{array}$ & & & $\begin{array}{c}0.0557 \\
(2.09)^{* *}\end{array}$ & & & $\begin{array}{l}0.0583 \\
(2.17)^{* *}\end{array}$ & & \\
\hline Grande empresa (250) & & $\begin{array}{c}0.0408 \\
(1.5)\end{array}$ & & & $\begin{array}{l}0.0487 \\
(1.8)^{*}\end{array}$ & & & $\begin{array}{l}0.0456 \\
(1.69)^{*}\end{array}$ & \\
\hline Pequena empresa & & & $\begin{array}{c}-0.0875 \\
(-3.04)^{\text {**** }}\end{array}$ & & & $\begin{array}{c}-0.1043 \\
(-3.62) * * *\end{array}$ & & & $\begin{array}{c}-0.0988 \\
(-3.45)^{* * *}\end{array}$ \\
\hline $\begin{array}{c}\text { W*LN PIB per capita } \\
\text { defasada }\end{array}$ & & & & & & & $\begin{array}{l}0.1039 \\
(2.17)^{* *}\end{array}$ & $\begin{array}{l}0.0956 \\
(2)^{* *}\end{array}$ & $\begin{array}{l}0.0694 \\
(1.43)\end{array}$ \\
\hline $\mathrm{W} *$ Escolaridade & & & & & & & $\begin{array}{l}0.0451 \\
(2.11)^{* *}\end{array}$ & $\begin{array}{l}0.0455 \\
(2.14)^{* *}\end{array}$ & $\begin{array}{c}0.0517 \\
(2.43)^{* *}\end{array}$ \\
\hline $\begin{array}{c}\mathrm{W} * \mathrm{Tx} \text { de crescimento } \\
\text { populacional }\end{array}$ & & & & & & & $\begin{array}{l}-0.2885 \\
(-1.89)^{*}\end{array}$ & $\begin{array}{l}-0.2900 \\
(-1.9)^{*}\end{array}$ & $\begin{array}{l}-0.2556 \\
(-1.69)^{*}\end{array}$ \\
\hline $\begin{array}{c}\mathrm{W} * \text { Grande empresa } \\
(500)\end{array}$ & & & & & & & $\begin{array}{l}-0.0010 \\
(-0.02)\end{array}$ & & \\
\hline $\begin{array}{c}\mathrm{W} * \text { Grande empresa } \\
(250)\end{array}$ & & & & & & & & $\begin{array}{l}0.0572 \\
(1.01)\end{array}$ & \\
\hline $\mathrm{W} *$ Pequena empresa & & & & & & & & & $\begin{array}{l}-0.1429 \\
(-2.41)^{* *}\end{array}$ \\
\hline Parâmetro espacial $(\lambda)$ & $\begin{array}{c}0.3257 \\
(9.95)^{* * * *}\end{array}$ & $\begin{array}{c}0.3234 \\
(9.86)^{* * * *}\end{array}$ & $\begin{array}{c}0.3173 \\
(9.59) * * *\end{array}$ & & & & & & \\
\hline Parâmetro espacial ( $\rho$ ) & & & & $\begin{array}{c}0.2760 \\
(10.19)^{* * *}\end{array}$ & $\begin{array}{c}0.2749 \\
(10.14)^{* * *}\end{array}$ & $\begin{array}{c}0.2718 \\
(10.03)^{* * *}\end{array}$ & $\begin{array}{c}0.3046 \\
(9.26)^{* * * *}\end{array}$ & $\begin{array}{c}0.3015 \\
(9.15)^{* * * *}\end{array}$ & $\begin{array}{c}0.2875 \\
(8.63)^{* * * *}\end{array}$ \\
\hline Observações & 1530 & 1530 & 1530 & 1530 & 1530 & 1530 & 1530 & 1530 & 1530 \\
\hline Log-likelihood (LIK) & 11.7994 & 11.7994 & 11.7994 & 11.7994 & 11.7994 & 11.7994 & 11.7994 & 11.7994 & 11.7994 \\
\hline
\end{tabular}

Nota: os números em parênteses são as estatísticas $\mathrm{t} .{ }^{* * *}, * *, *$ indicam que os parâmetros estimados são significativamente diferentes de zero ao nível de 1, 5 e $10 \%$.

Fonte: IBGE, Ipeadata e RAIS. Elaborado pelos autores.

\section{Considerações finais}

O objetivo deste artigo foi analisar de maneira empírica qual a relação existente entre o tamanho das empresas e o crescimento econômico das microrregiões brasileiras durante o período de 1999 a 2009. A estratégia empírica 
utilizada consiste na elaboração de um painel de dados para estimação através de efeitos fixos, bem como de análises que controlem os efeitos da dependência espacial e da heterogeneidade espacial.

Os resultados encontrados a partir de ambas as estimações - GMM e dependência espacial - indicam que a presença de grandes empresas está positivamente relacionada com a taxa de crescimento do PIB per capita. O contrário ocorre em relação às pequenas empresas.

Os modelos de econometria espacial possibilitaram, ainda, inferir que a presença de pequenas empresas nas regiões vizinhas teve uma relação negativa com taxa de crescimento econômico. Com relação à influência das grandes empresas nas regiões vizinhas, não foram obtidos resultados significativos.

Levando em consideração a heterogeneidade espacial verificada na amostra, os efeitos da dependência espacial na relação entre tamanho das empresas e crescimento econômico são estimados separadamente para cada regime. Os resultados obtidos nessas análises se mostraram diferentes do encontrado nas análises relativas ao Brasil como um todo.

Nas microrregiões do Norte e Nordeste do Brasil, o tamanho da empresa parece não influenciar na taxa de crescimento econômico, uma vez que os resultados não apresentaram significância estatística. Já nas regiões Sul e Sudeste, a relação encontrada é similar ao Brasil como um todo, com as grandes empresas contribuindo para uma maior taxa de crescimento do PIB per capita, enquanto que as pequenas empresas apresentaram uma relação negativa com o crescimento econômico.

Diferem entre os dois regimes espaciais também os resultados referentes à importância do capital humano para o crescimento econômico. Nas regiões de renda per capita mais elevada, a variável que indica escolaridade apresentou uma relação positiva com o crescimento econômico, ao passo que, nas regiões com renda per capita menor, verificou-se um sinal negativo da variável relativa à escolaridade.

Em geral, os resultados encontrados neste trabalho mostram que as grandes empresas tendem a contribuir mais para o crescimento econômico regional do que as pequenas. Considerando a literatura sobre o tema, poder-se-ia creditar esses resultados às características peculiares das grandes empresas, tais como: maior integração internacional, maior produtividade, maior acesso ao crédito e maior capacidade de inovação.

Seguindo a mesma linha de raciocínio, os resultados distintos encontrados para as duas regióes brasileiras - coeficientes significativos para tamanho de empresas apenas quando as regiões Sul, Sudeste e Centro-Oeste são analisadas -, sugerem que as características inerentes às grandes empresas sejam mais bem exploradas em localidades com nível de desenvolvimento mais elevado. Em outras palavras, fatores como produtividade, inovação e internacionalização, típicos das empresas maiores, têm seus potenciais mais bem explorados em regiões de elevado desenvolvimento local.

Já a relação negativa entre pequenas empresas e crescimento econômico pode estar associada à qualidade das instituições e aos níveis de capital humano, que não proporcionam um ambiente propício para a expansão do empreendedorismo produtivo (Dias e McDermott, 2006), fazendo com que o 
empreendedorismo ocorra mais pela necessidade de empreender do que pela geração de oportunidades empresariais.

\section{REFERÊNCIAS}

ACS, Z.; DESAI, S.; HESSELS, J. Entrepreneurship, economic development and institutions. Small Business Economics, n. 31, p. 219-234, 2008.

ANSELIN, L. Spatial econometrics: Methods and models. Kluwer, Dordrecht, 1988.

ANSELIN, L. Local indicators of spatial association - LISA. Geographical Analysis, v. 27, n. 2, p. 93-115, 1995.

ANSELIN, L. The moran scatterplot as an ESDA tool to assess local instability in spatial association. In: FISCHER, M.; SCHOLTEN, H.; UNWIN, D. (orgs) Spatial Analytical Perspectives on GIS. Taylor and Francis, London, p. 111-125, 1996.

ARAÚJO, G, D.; HIRATUKA, C.Exportações das firmas domésticas e influências das firmas transnacionais. In: DE NEGRI, J, A.; ARAÚJO, B, C. (orgs) As empresas brasileiras e o comércio internacional. IPEA, Brasília, p. 317-339, 2006.

ARBIA, G.; LE GALLO, J.; PIRAS, G. Does evidence on regional convergence depend on the estimation strategy?, Outcomes from analysis of a set of NUTS2 EU regions. Spatial Economic Analysis, n. 3, p. 209-224, 2008.

ARELLANO, M.; BOVER, O. Another look at the instrumental-variable estimation of error-component models, Journal of Econometrics, n. 68, p. 29-51, 1991.

BARRO, J, B. Economic growth in a cross section of countries, The Quarterly Journal of Economics, v.106, n. 2, p. 407-443, 1991.

BADINGER, H.; MÜLLER, W.; TONDL, G. Regional convergence in the European Union 1985-1999: A spatial dynamic panel analysis, Regional Studies, v. 38, n. 3, p. 241-253, 2004.

BECK, T.; DEMIRGUC-KUNT, A.; LEVINE, R. SMEs, growth, and poverty: Crosscountry evidence. Journal of Economic Growth n. 10, p. 199-229, 2005.

BIESEBROECK, J, V. Firm size matters: growth and productivity growth in African manufacturing. Economic Development and Cultural Change, v. 53, n. 3, p. 545-583, 2005.

BLUNDELL, R; BOND, S. Initial conditions and moment restrictions in dynamic panel data models, Journal of Econometrics, n. 87, p. 115-143, 1988. 
BOND, S.; HOEFFLER, A.; TEMPLE, J. GMM estimation of empirical growth models, Centre for Economic Policy Research, Discussion Paper, n. 3048, p. 1-33, 2001.

BRUCE, D.; DESKINS, J. A.; HILL, B. C.; RORK, J. C. (Small) business activity and state economic growth: does size matter? Regional Studies, v. 43, n. 2, p. 229-245, 2009.

CRAVO, T, A.; BECKER, B.; GOURLAY, A. Regional growth and SMEs in Brazil: A spatial panel approach, Regional Studies, p. 1-22, 2014.

CRAVO, T, A.; GOURLAY, A.; BECKER, B. SMEs and regional economic growth in Brazil, Small Business Economics, n. 14, p. 1-14, 2012.

CRAVO, T, A. SMEs and economic growth in the Brazilian micro-regions, Papers in Regional Science, v. 89, n. 4, p. 711-735, 2010.

DALL'ERBA, S.; LE GALLO, J. Regional convergence and the impact of European structural funds over 1985-1999: A spatial econometric analysis. Papers in Regional Science, v. 87, n. 219-245, 2008.

DE NEGRI, J.A. Rendimentos Crescentes de Escala e o Desempenho Exportador das Firmas no Brasil. In: DE NEGRI, J. A.; ARAÚJO, B. C. O. (org). As Empresas brasileiras e o comércio internacional. Brasília: IPEA, p.189-214, 2006.

DIAS, J.; MCDERMOTT, J. Institutions, education, and development: The role of entrepreneurs. Journal of Development Economics, n. 80, p. 299-328, 2006.

DURLAUF, S, N.; JOHNSON, P, A.; TEMPLE, J, R, W. Growth Econometrics. In: AGHION, P.; DURLAUF, S. (Eds). Handbook of Economic Growth, Elsevier, p. 555$677,2005$.

ELHORST, J, P. Spatial panel data models. In: FISCHER, M.; GETIS, A. (Eds). Handbook of Applied Spatial Analysis, Springer, p. 377-407, 2010.

ERTUR, C.; KOCH, W. Growth, technological interdependence ans spatial extenalities: Theory and evidence. Journal of Applied Econometrics, v. 22, p. 1033$1062,2007$.

ERTUR, C.; LE GALLO, J.; BAUMONT, C. The European regional convergence process, 1980-1995: Do spatial regimes and spatial dependence matters?. International Regional Science Review, v. 29, n.1, p. 3-34, 2006.

ESTEVE-PEREZ, S. et al.. A survival analysis of manufacturing firms in export markets. In: ARAUZO-CAROD, J. M.; MANJON-ANTOLIN, M. C. Entrepreneurship, Industrial Location, and Economic Growth. Edward Elgar Publishing Limited, 2007.

GOMES, V.; ELLERY Jr., R. Perfil da exportações, produtividade e tamanho das firmas no Brasil. Revista Brasileira de Economia , v. 61, n.1, p. 33-48, 2007. 
IDSON, T, L.; OI, W, Y. Workers are more productive in large firms, The American Economic Review, v. 89, n. 2, p. 104-108, 1999.

KOMAREK, M, T,; LOVERIDGE, S. Firm sizes and economic development: estimating long-term effects on U.S. county growth, 1990-2000. Journal of Regional Science, p.1-18, 2015.

LA ROVERE, R. L.; SHEHATA, L. D. Políticas de apoio à micro e pequenas empresas e desenvolvimento local: alguns pontos de reflexão. REDES, v.11, n. 3, p. 9-24, 2006.

LAURINI, M.; ANDRADE, E.; VALLS, P. Income convergence clubs for Brazilian municipalities: a non-parametric analysis, Applied Economics, v. 37, p. 2099-2118, 2005.

LEE, K.; KIM, B.Y.; PARK, Y.Y.; SANIDAS, E. Big businesses and economic growth: Identifying a binding constraint for growth with country panel analysis, Journal of Comparative Economics, v. 41, p. 561-582, 2012.

LeSAGE, J, P.; PACE, R, K. Introduction to spatial econometrics. CRC Press/ Taylor \& Francis, London, 2009.

LIU X.; SHU C. Determinants of exports performance: evidence from Chinese industries, Economics of Planning, v. 36, n. 1, p. 45-67, 2003.

LING-YEE, L; OGUNMOKUM, O. The influence of interfirm relational capabilities on export advantage and performance: an empirical analysis. International Business Review, v. 10, p. 399-420, 2001.

LOVERIDGE, S.; NIZALOV, D. Operationalizing the entrepreneurial pipeline theory: an empirical assessment of the optimal size distribution of local firms. Economic Development Quarterly, v. 21, n. 3, p. 244-262, 2007.

MANKIW, N, G.; ROMER, D.; WEIL, D, N. A contribution to the empirics of economic growth. Quarterly Journal of Economics, v. 107, p. 407-437, 1992.

MOHL, P.; HAGEN, T. Do structural funds promote regional growth? New evidence from various panel data approaches. Regional Science and Urban Economics, n. 40, p. 353-365, 2010.

MUELLER, P. Exploiting entrepreneurial opportunities: The impact of entrepreneurship on growth. Small Business Economics, n. 28, p. 355-362, 2007.

PAGANO, P.; SCHIVARDI, F. Firm size distribution and growth. The Scandinavian Journal of Economics, v. 105, n. 2, p. 255-274, 2003. 
PERIUS, N. M.; WITTMANN, M. L. Micro e pequenas empresas no cenário do desenvolvimento contemporâneo. REDES, v. 8, n. 1, p. 165-177, 2003.

RAMAJO, J.; MÁRQUEZ, M, A.; HEWINGS, G, J, D.; SALINAS, M, M. Spatial heterogeneity and interregional spillovers in the European Union: Do cohesion policies encourage convergence across regions? European Economic Review, n. 52, p. 551-567, 2008.

REY, S, J.; MONTOURI, B, D. US regional income convergence: A spatial econometric perspective, Regional Studies, v. 32, n.2, p. 143-156, 1999.

SHAFFER, S. Firm size and economic growth. Economic Letters, v. 76, p. 195-203, 2002.

SHAFFER, S. Establishment size and local employment growth. Small Business Economics, n. 29, p. 439-454, 2006.

SILVA, C. E. L. O impacto do bndesexim no tempo de permanência das firmas brasileiras no mercado internacional: uma análise a partir dos microdados, Planejamento e Políticas Públicas, n. 38, p. 9-36, 2012.

SILVEIRA-NETO, R.; AZZONI, C, R. Location and regional income disparity dynamics: The brazilian case, Papers in Regional Science, v. 85, p. 599-613, 2006.

VAN STEL, A.; CARREE, M.; THURIK, R. The effect of entrepreneurial activity on national economic growth. Small Business Economics n. 24, p. 311-321, 2005.

ZWEIFEL, P. Services in Switzerland: Structure, performance, and implications of European economic integration, 1993. Disponível em:

http://www.getcited.org/pub/103104187 . Acesso em: 01 maio 2014.

Malizia, Matildea. Licenciada en Trabajo Social, Doctora en Ciencias Sociales, Centro de Estudios sobre Territorio y Hábitat Popular (FAU - UNT);

matumalizia@yahoo.com.ar

Boldrini, Paula. Arquitecta, Doctora en Ciencias Sociales, Centro de Estudios sobre Territorio y Hábitat Popular (FAU - UNT); paula_boldrini@hormail.com

Ruiz Peyré, Fernando. Licenciado en Geografia, Doctor en Ciencias Naturales; Institut für Geographie, Universität Innsbruck (Austria); fernando.ruiz-peyre@uibk.ac.at 
APÊNDICE A

Tabela A.1 - Estimações de painel espacial com matriz k-vizinhos ( $k=5)$

\begin{tabular}{|c|c|c|c|c|c|c|c|c|c|}
\hline \multirow{2}{*}{$\begin{array}{l}\text { Microrregiões } \\
\text { Estimação }\end{array}$} & \multirow{2}{*}{\multicolumn{3}{|c|}{ SEM }} & \multirow{2}{*}{\multicolumn{3}{|c|}{ SAR }} & \multirow{2}{*}{\multicolumn{3}{|c|}{ SDM }} \\
\hline & & & & & & & & & \\
\hline $\begin{array}{c}\text { LN PIB per capita } \\
\text { defasada }\end{array}$ & $\begin{array}{c}-0.67 \\
(-38.17)\end{array}$ & $\begin{array}{c}-0.67 \\
(-38.24)^{* * * *}\end{array}$ & $\begin{array}{c}-0.67 \\
(-38.29)^{* * * *}\end{array}$ & $\begin{array}{c}-0.61 \\
(-36.2)^{* * *}\end{array}$ & $\begin{array}{c}-0.61 \\
(-36.29)^{* * * *}\end{array}$ & $\begin{array}{c}-0.61 \\
(-36.37)^{* * * *}\end{array}$ & $\begin{array}{c}-0.6627 \\
(-37.18)^{* * *}\end{array}$ & $\begin{array}{c}-0.66 \\
(-37.26)^{* * * *}\end{array}$ & $\begin{array}{c}-0.67 \\
(-37.32)^{* * *}\end{array}$ \\
\hline Escolaridade & $\begin{array}{c}-0.01 \\
(-2.18)^{* *}\end{array}$ & $\begin{array}{c}-0.01 \\
(-2.15)^{* *}\end{array}$ & $\begin{array}{c}-0.01 \\
(-2.3)^{* *}\end{array}$ & $\begin{array}{c}-0.01 \\
(-1.32)\end{array}$ & $\begin{array}{c}-0.01 \\
(-1.33)\end{array}$ & $\begin{array}{l}-0.01 \\
(-1.5)\end{array}$ & $\begin{array}{c}-0.01 \\
(-2.39)^{* *}\end{array}$ & $\begin{array}{c}-0.01 \\
(-2.37)^{* *}\end{array}$ & $\begin{array}{c}-0.01 \\
(-2.54)^{* *}\end{array}$ \\
\hline $\begin{array}{l}\text { Tx de crescimento } \\
\text { populacional }\end{array}$ & $\begin{array}{c}-0.41 \\
(-8.71)^{* * * *}\end{array}$ & $\begin{array}{c}-0.41 \\
(-8.75)^{* * *}\end{array}$ & $\begin{array}{c}-0.41 \\
(-8.76)^{* * *}\end{array}$ & $\begin{array}{c}-0.39 \\
(-8.47)^{* * * *}\end{array}$ & $\begin{array}{c}-0.39 \\
(-8.52)^{* * * *}\end{array}$ & $\begin{array}{c}-0.39 \\
(-8.58)^{* * * *}\end{array}$ & $\begin{array}{c}-0.40 \\
(-8.56)^{* * * *}\end{array}$ & $\begin{array}{c}-0.41 \\
(-8.6)^{* * * *}\end{array}$ & $\begin{array}{c}-0.41 \\
(-8.64)^{* * * *}\end{array}$ \\
\hline Grande empresa (500) & $\begin{array}{c}0.02 \\
(-1.02)\end{array}$ & & & $\begin{array}{c}0.03 \\
(-1.52)\end{array}$ & & & $\begin{array}{r}0.02 \\
-1.15\end{array}$ & & \\
\hline Grande empresa (250) & & $\begin{array}{c}0.03 \\
(2.2)^{* * *}\end{array}$ & & & $\begin{array}{c}0.04 \\
(2.59)^{* *}\end{array}$ & & & $\begin{array}{c}0.04 \\
(2.22)^{* *}\end{array}$ & \\
\hline Pequena empresa & & & $\begin{array}{c}-0.04 \\
(-2.71)^{* * *}\end{array}$ & & & $\begin{array}{c}-0.05 \\
(-3.29) * * *\end{array}$ & & & $\begin{array}{c}-0.04 \\
(-2.94)^{* * *}\end{array}$ \\
\hline $\begin{array}{c}\mathrm{W}^{*} \mathrm{LN} \text { PIB per capita } \\
\text { defasada }\end{array}$ & & & & & & & $\begin{array}{c}0.27 \\
(8.03)^{* * * *}\end{array}$ & $\begin{array}{l}0.27 \\
(7.95)^{* * * *}\end{array}$ & $\begin{array}{c}0.26 \\
(7.77)^{* * * *}\end{array}$ \\
\hline $\mathrm{W}^{*}$ Escolaridade & & & & & & & $\begin{array}{c}0.03 \\
(3.34)^{* * * *}\end{array}$ & $\begin{array}{c}0.03 \\
(3.29)^{* * * *}\end{array}$ & $\begin{array}{c}0.03 \\
(3.4)^{* * *}\end{array}$ \\
\hline $\begin{array}{c}\mathrm{W}^{*} \mathrm{Tx} \text { de crescimento } \\
\text { populacional }\end{array}$ & & & & & & & $\begin{array}{c}0.16 \\
(1.78)^{*}\end{array}$ & $\begin{array}{c}0.16 \\
(1.81)^{*}\end{array}$ & $\begin{array}{c}0.15 \\
(1.66)^{*}\end{array}$ \\
\hline $\begin{array}{c}\mathrm{W} * \text { Grande empresa } \\
(500)\end{array}$ & & & & & & & $\begin{array}{c}0.01 \\
(-0.17)\end{array}$ & & \\
\hline $\begin{array}{c}\mathrm{W} * \text { Grande empresa } \\
(250)\end{array}$ & & & & & & & & $\begin{array}{r}0.00 \\
-0.11\end{array}$ & \\
\hline $\mathrm{W} *$ Pequena empresa & & & & & & & & & $\begin{array}{c}-0.02 \\
(-0.59)\end{array}$ \\
\hline Parâmetro espacial $(\lambda)$ & $\begin{array}{c}0.45002 \\
(20.04)^{* * * *}\end{array}$ & $\begin{array}{c}0.44991 \\
(20.02)^{* * * *}\end{array}$ & $\begin{array}{c}0.44992 \\
(20.01)^{* * * *}\end{array}$ & & & & & & \\
\hline Parâmetro espacial ( $\rho$ ) & & & & $\begin{array}{c}0.34294 \\
(17.01)^{* * *}\end{array}$ & $\begin{array}{c}0.34262 \\
(17.01)^{* * * *}\end{array}$ & $\begin{array}{c}0.34335 \\
(17.06)^{* * * *}\end{array}$ & $\begin{array}{c}0.44206 \\
(19.53)^{* * * *}\end{array}$ & $\begin{array}{c}0.44166 \\
(19.48)^{* * *}\end{array}$ & $\begin{array}{c}0.44047 \\
(19.4)^{* * *}\end{array}$ \\
\hline Observações & 2790 & 2790 & 2790 & 2790 & 2790 & 2790 & 2790 & 2790 & 2790.00 \\
\hline Log-likelihood (LIK) & 12. 8221 & 12. 8221 & 12. 8221 & 12. 8221 & 12. 8221 & 12. 8221 & 12. 8221 & 12. 8221 & 12. 8221 \\
\hline
\end{tabular}

Nota: Os Números em parênteses são as estatísticas t. ***, ** * indicam que os parâmetros estimados são significativamente diferentes de zero ao nível de 1, 5 e 10\%. Em todas as estimações as variáveis explicativas foram tratadas como potencialmente endógenas. Foram incluídas dummies de ano como controle.

Fonte: IBGE, IPEADATA e RAIS. Elaborado pelo autor. 
APÊNDICE B - I de Moran local (LISA)

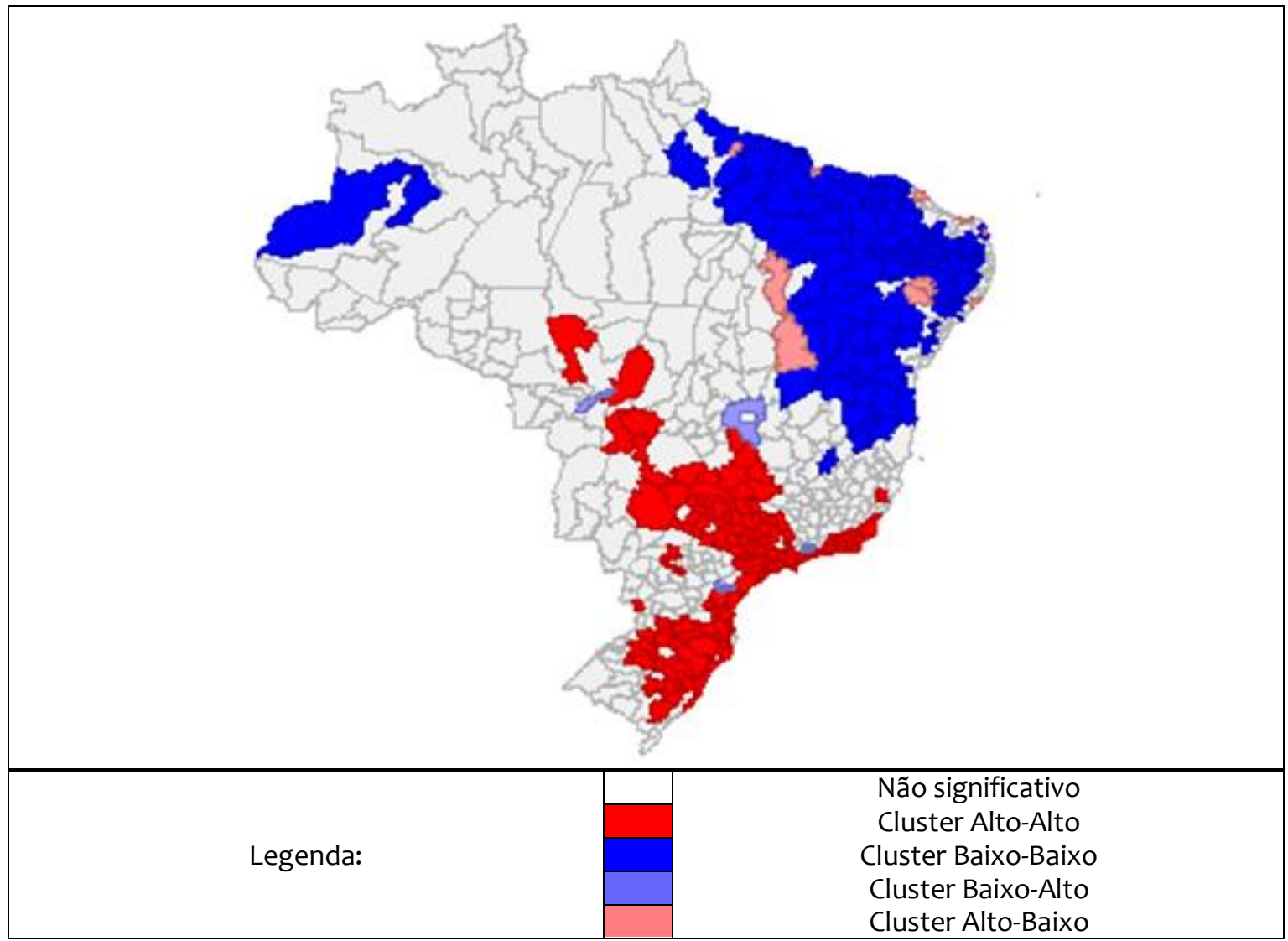

Figura B.1 - I de Moran local (LISA) do logaritmo natural do PIB per capita no ano inicial com matriz k-vizinhos ( $k=5)$

Fonte: IBGE e IPEADATA. Elaborado pelos autores. 
APÊNDICE C - Painel espacial em diferentes regimes espaciais (Matriz k=5)

Tabela C.1 - Estimações de painel espacial para as regiões norte e nordeste

\begin{tabular}{|c|c|c|c|c|c|c|c|c|c|}
\hline \multirow{2}{*}{$\begin{array}{l}\text { Microrregiões } \\
\text { Estimação } \\
\end{array}$} & \multirow{2}{*}{\multicolumn{3}{|c|}{ SEM }} & \multirow{2}{*}{\multicolumn{3}{|c|}{ SAR }} & \multirow{2}{*}{\multicolumn{3}{|c|}{ SDM }} \\
\hline & & & & & & & & & \\
\hline $\begin{array}{c}\text { LN PIB per capita } \\
\text { defasada }\end{array}$ & $\begin{array}{c}-0.6369 \\
(-24.43) * * *\end{array}$ & $\begin{array}{c}-0.6377 \\
(-24.48)^{* * * *}\end{array}$ & $\begin{array}{c}-0.6394 \\
(-24.48)^{* * * *}\end{array}$ & $\begin{array}{c}-0.6037 \\
(-23.6)^{* * * *}\end{array}$ & $\begin{array}{c}-0.6044 \\
(-23.65)^{* * * *}\end{array}$ & $\begin{array}{c}-0.6059 \\
(-23.65)^{* * * *}\end{array}$ & $\begin{array}{c}-0.6353 \\
(-23.9)^{* * * *}\end{array}$ & $\begin{array}{c}-0.6376 \\
(-24.03) * * *\end{array}$ & $\begin{array}{c}-0.6391 \\
(-24.05)^{* * *}\end{array}$ \\
\hline Escolaridade & $\begin{array}{c}-0.0235 \\
(-3.91)^{* * *}\end{array}$ & $\begin{array}{c}-0.0231 \\
(-3.86) * * *\end{array}$ & $\begin{array}{c}-0.0238 \\
(-3.98)^{* * *}\end{array}$ & $\begin{array}{c}-0.0244 \\
(-4.07)^{* * *}\end{array}$ & $\begin{array}{l}-0.0239 \\
(-4)^{* * * *}\end{array}$ & $\begin{array}{c}-0.0246 \\
(-4.13)^{* * *}\end{array}$ & $\begin{array}{c}-0.0240 \\
(-3.97) * * *\end{array}$ & $\begin{array}{c}-0.0232 \\
(-3.85) * * *\end{array}$ & $\begin{array}{c}-0.0240 \\
(-3.98) * * *\end{array}$ \\
\hline $\begin{array}{l}\text { Tx de crescimento } \\
\text { populacional }\end{array}$ & $\begin{array}{c}-0.4006 \\
(-6.66) * * *\end{array}$ & $\begin{array}{c}-0.4005 \\
(-6.66)^{* * * *}\end{array}$ & $\begin{array}{c}-0.4019 \\
(-6.68)^{* * * *}\end{array}$ & $\begin{array}{c}-0.3697 \\
(-6.24)^{* * * *}\end{array}$ & $\begin{array}{c}-0.3703 \\
(-6.25)^{* * *}\end{array}$ & $\begin{array}{c}-0.3725 \\
(-6.29)^{* * * *}\end{array}$ & $\begin{array}{c}-0.3999 \\
(-6.61)^{* * *}\end{array}$ & $\begin{array}{c}-0.4007 \\
(-6.62) * * *\end{array}$ & $\begin{array}{c}-0.3995 \\
(-6.59) * * *\end{array}$ \\
\hline Grande empresa (500) & $\begin{array}{l}0.0084 \\
(0.33)\end{array}$ & & & $\begin{array}{l}0.0059 \\
(0.23)\end{array}$ & & & $\begin{array}{c}0.0050 \\
(0.19)\end{array}$ & & \\
\hline Grande empresa (250) & & $\begin{array}{l}0.0294 \\
(1.43)\end{array}$ & & & $\begin{array}{c}0.0298 \\
(1.4)\end{array}$ & & & $\begin{array}{c}0.0289 \\
(1.38)^{* * * *}\end{array}$ & \\
\hline Pequena empresa & & & $\begin{array}{c}-0.0231 \\
(-1.3)\end{array}$ & & & $\begin{array}{l}-0.0229 \\
(-1.24)\end{array}$ & & & $\begin{array}{l}-0.0212 \\
(-1.16)\end{array}$ \\
\hline $\begin{array}{c}\text { W*LN PIB per capita } \\
\text { defasada }\end{array}$ & & & & & & & $\begin{array}{c}0.2349 \\
(4.34) * * *\end{array}$ & $\begin{array}{c}0.2363 \\
(4.35)^{* * * *}\end{array}$ & $\begin{array}{c}0.2401 \\
(4.41)^{* * * *}\end{array}$ \\
\hline $\mathrm{W} *$ Escolaridade & & & & & & & $\begin{array}{l}0.0160 \\
(1.24)\end{array}$ & $\begin{array}{l}0.0187 \\
(1.46)\end{array}$ & $\begin{array}{l}0.0189 \\
(1.49)\end{array}$ \\
\hline $\begin{array}{l}\mathrm{W} * \mathrm{Tx} \text { de crescimento } \\
\text { populacional }\end{array}$ & & & & & & & $\begin{array}{c}0.1448 \\
(1.24)\end{array}$ & $\begin{array}{l}0.1370 \\
(1.18)\end{array}$ & $\begin{array}{c}0.1382 \\
(1.18)\end{array}$ \\
\hline $\mathrm{W}^{*}$ Grande empresa & & & & & & & $\begin{array}{c}-0.0731 \\
(-1.28)\end{array}$ & & \\
\hline $\begin{array}{c}\mathrm{W}^{*} \text { Grande empresa } \\
(250)\end{array}$ & & & & & & & & $\begin{array}{l}-0.0191 \\
(-0.39)\end{array}$ & \\
\hline $\mathrm{W} *$ Pequena empresa & & & & & & & & & $\begin{array}{c}0.0348 \\
(0.83)\end{array}$ \\
\hline Parâmetro espacial $(\lambda)$ & $\begin{array}{c}0.3332 \\
(8.67) * * *\end{array}$ & $\begin{array}{c}0.3335 \\
(8.68)^{* * * *}\end{array}$ & $\begin{array}{c}0.3350 \\
(8.72)^{* * * *}\end{array}$ & & & & & & \\
\hline Parâmetro espacial ( $\rho$ ) & & & & $\begin{array}{c}0.2367 \\
(6.96)^{* * *}\end{array}$ & $\begin{array}{c}0.2370 \\
(6.98)^{* * * *}\end{array}$ & $\begin{array}{c}0.2387 \\
(7.02)^{* * *}\end{array}$ & $\begin{array}{c}0.3326 \\
(8.65)^{* * *}\end{array}$ & $\begin{array}{c}0.3336 \\
(8.68)^{* * * *}\end{array}$ & $\begin{array}{l}0.3342 \\
(8.7)^{* * * *}\end{array}$ \\
\hline Observações & 1260 & 1260 & 1260 & 1260 & 1260 & 1260 & 1260 & 1260 & 1260 \\
\hline Log-likelihood (LIK) & 12.8221 & 12.8221 & 12.8221 & 12.8221 & 12.8221 & 12.8221 & 12.8221 & 12.8221 & 12.8221 \\
\hline
\end{tabular}

Nota: Os Números em parênteses são as estatísticas t. ***, **, * indicam que os parâmetros estimados são significativamente diferentes de zero ao nível de 1, 5 e 10\%. Em todas as estimações as variáveis explicativas foram tratadas como potencialmente endógenas. Foram incluídas dummies de ano como controle.

Fonte: IBGE, IPEADATA e RAIS. Elaborado pelo autor. 
Tabela C.2 - Estimações de painel espacial para as regiões sul, sudeste e centro-oeste.

\begin{tabular}{|c|c|c|c|c|c|c|c|c|c|}
\hline Microrregiões & & & & & & & & & \\
\hline Estimação & & SEM & & & SAR & & & SDM & \\
\hline $\begin{array}{c}\text { LN PIB per capita } \\
\text { defasada }\end{array}$ & $\begin{array}{c}-0.705 \\
(-29.87)^{* * * *}\end{array}$ & $\begin{array}{c}-0.706 \\
(-29.9) * * *\end{array}$ & $\begin{array}{c}-0.709 \\
(-30.08)^{* * * *}\end{array}$ & $\begin{array}{c}-0.634 \\
(-28.47)^{* * * *}\end{array}$ & $\begin{array}{c}-0.634 \\
(-28.46)^{* * *}\end{array}$ & $\begin{array}{c}-0.640 \\
(-28.75) * * *\end{array}$ & $\begin{array}{c}-0.699 \\
(-28.85) * * *\end{array}$ & $\begin{array}{c}-0.699 \\
(-28.83) * * * *\end{array}$ & $\begin{array}{c}-0.701 \\
(-28.98)^{* * * *}\end{array}$ \\
\hline Escolaridade & $\begin{array}{c}0.027 \\
(2.45)^{* *}\end{array}$ & $\begin{array}{c}0.026 \\
(2.43)^{* *}\end{array}$ & $\begin{array}{c}0.027 \\
(2.51)^{* * *}\end{array}$ & $\begin{array}{c}0.035 \\
(3.29)^{* * *}\end{array}$ & $\begin{array}{c}0.034 \\
(3.18)^{* * * *}\end{array}$ & $\begin{array}{c}0.035 \\
(3.27)^{* * *}\end{array}$ & $\begin{array}{c}0.027 \\
(2.47)^{* * *}\end{array}$ & $\begin{array}{c}0.027 \\
(2.48)^{* *}\end{array}$ & $\begin{array}{c}0.027 \\
(2.53)^{* *}\end{array}$ \\
\hline $\begin{array}{l}\text { Tx de crescimento } \\
\text { populacional }\end{array}$ & $\begin{array}{c}-0.396 \\
(-5.2) * * *\end{array}$ & $\begin{array}{c}-0.402 \\
(-5.28)^{* * *}\end{array}$ & $\begin{array}{c}-0.399 \\
(-5.25)^{* * *}\end{array}$ & $\begin{array}{c}-0.427 \\
(-5.83) * * *\end{array}$ & $\begin{array}{c}-0.432 \\
(-5.89)^{* * *}\end{array}$ & $\begin{array}{c}-0.427 \\
(-5.85)^{* * * *}\end{array}$ & $\begin{array}{c}-0.392 \\
(-5.14) * * *\end{array}$ & $\begin{array}{c}-0.393 \\
(-5.14)^{* * *}\end{array}$ & $\begin{array}{c}-0.392 \\
(-5.15)^{* * * *}\end{array}$ \\
\hline Grande empresa (500) & $\begin{array}{l}0.031 \\
(1.23)\end{array}$ & & & $\begin{array}{c}0.054 \\
(2.11)^{* *}\end{array}$ & & & $\begin{array}{l}0.040 \\
(1.55)\end{array}$ & & \\
\hline Grande empresa (250) & & $\begin{array}{l}0.042 \\
(1.63)\end{array}$ & & & $\begin{array}{c}0.053 \\
(2.04) * *\end{array}$ & & & $\begin{array}{l}0.042 \\
(1.63)\end{array}$ & \\
\hline Pequena empresa & & & $\begin{array}{c}-0.083 \\
(-3.02)^{* * * *}\end{array}$ & & & $\begin{array}{c}-0.108 \\
(-3.89) * * *\end{array}$ & & & $\begin{array}{c}-0.088 \\
(-3.21)^{* * *}\end{array}$ \\
\hline $\begin{array}{c}\text { W*LN PIB per capita } \\
\text { defasada }\end{array}$ & & & & & & & $\begin{array}{c}0.258 \\
(5.64)^{* * * *}\end{array}$ & $\begin{array}{c}0.268 \\
(-5.83)^{* * * *}\end{array}$ & $\begin{array}{c}0.248 \\
(5.28) * * *\end{array}$ \\
\hline $\mathrm{W}^{*}$ Escolaridade & & & & & & & $\begin{array}{l}0.022 \\
(1.07)\end{array}$ & $\begin{array}{l}0.019 \\
(0.92)\end{array}$ & $\begin{array}{l}0.020 \\
(0.94)\end{array}$ \\
\hline $\begin{array}{c}\mathrm{W} * \mathrm{Tx} \text { de crescimento } \\
\text { populacional }\end{array}$ & & & & & & & $\begin{array}{l}-0.038 \\
(-0.27)\end{array}$ & $\begin{array}{l}0.001 \\
(0.01)\end{array}$ & $\begin{array}{l}-0.010 \\
(-0.07)\end{array}$ \\
\hline $\begin{array}{c}\mathrm{W} * \text { Grande empresa } \\
(500)\end{array}$ & & & & & & & $\begin{array}{l}0.082 \\
(1.55)\end{array}$ & & \\
\hline $\begin{array}{c}\mathrm{W} * \text { Grande empresa } \\
(250)\end{array}$ & & & & & & & & $\begin{array}{l}-0.005 \\
(0.09)\end{array}$ & \\
\hline $\mathrm{W} *$ Pequena empresa & & & & & & & & & $\begin{array}{l}-0.051 \\
(-0.91)\end{array}$ \\
\hline Parâmetro espacial $(\lambda)$ & $\begin{array}{c}0.484 \\
(16.61) * * *\end{array}$ & $\begin{array}{c}0.485 \\
(16.67) * * *\end{array}$ & $\begin{array}{c}0.482 \\
(16.47)^{* * * *}\end{array}$ & & & & & & \\
\hline Parâmetro espacial ( $\rho$ ) & & & & $\begin{array}{c}0.377 \\
(14.81)^{* * * *}\end{array}$ & $\begin{array}{c}0.377 \\
(14.81)^{* * *}\end{array}$ & $\begin{array}{c}0.375 \\
(14.77)^{* * *}\end{array}$ & $\begin{array}{c}0.469 \\
(15.89)^{* * * *}\end{array}$ & $\begin{array}{c}0.473 \\
(16.02)^{* * * *}\end{array}$ & $\begin{array}{c}0.464 \\
(15.54)^{* * * *}\end{array}$ \\
\hline Observações & 1530 & 1530 & 1530 & 1530 & 1530 & 1530 & 1530 & 1530 & 1530 \\
\hline Log-likelihood (LIK) & 11.7994 & 11.7994 & 11.7994 & 11.7994 & 11.7994 & 11.7994 & 11.7994 & 11.7994 & 11.7994 \\
\hline
\end{tabular}

Nota: Os Números em parênteses são as estatísticas t. ***, **, * indicam que os parâmetros estimados são significativamente diferentes de zero ao nível de 1, 5 e 10\%. Em todas as estimações as variáveis explicativas foram tratadas como potencialmente endógenas. Foram incluídas dummies de ano como controle.

Fonte: IBGE, IPEADATA e RAIS. Elaborado pelo autor. 